\title{
DIRECT OPTIMALITY THEORY: REPRESENTATION AS PURE MARKEDNESS
}

\author{
CHRIS GoLSTON \\ California State University Fresno
}

I present a model of phonological representation which represents morphemes in terms of constraint violations rather than strings of segments or root nodes. The formalism allows representation to be uniform throughout the phonology, mandates permanent underspecification of unmarked structure, derives the linear order of segments within a morpheme, and allows representation and evaluation to be conflated. Marked types of morphology (infixes, circumfixes, zero affixes; subtractive, reduplicative and templatic morphology) are represented in exactly the same way as roots. The markedness of such morphology is argued to follow from the high ranking of the violated constraints in question.*

1. InTRODUCTION. In this article I argue for a model of morphology and phonology, DIRECT OPTIMALITY THEORY (direct OT), in which phonological form is represented purely in terms of markedness rather than by strings of segments. I formalize this in terms of distinctive violation of phonological well-formedness constraints.

To see how this works, consider the following autosegmental representation of three.

(1) $[\theta$ xi:]

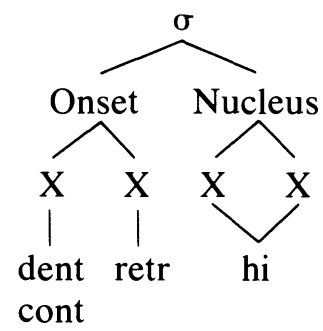

Such a representation has a syllable node with onset and nucleus, four timing slots (X) and a number of distinctive features linked to them. Consider now the type of representation that will be argued for here, where columns are phonological constraints and $\mathrm{R}$ represents distinctive violation of these constraints by a root.

\footnotetext{
* The work presented here was carried out as part of Sonderforschungsbereich 282 Theorie des Lexikons at Heinrich Heine University (Düsseldorf). I'd like to thank my colleagues there and at the University of Köln for their help in the research presented here. Special thanks to Cheryl Chan, Mike Hammond, Karijn Helsloot, René Kager, Wolfgang Kehrein, Utz Maas, Martin Neef, Albert Ortmann, Tomas Riad, Keren Rice, Péter Siptár, Markus Walther, Richard Wiese, Dieter Wunderlich, and two anonymous Language reviewers for comments on earlier drafts of this paper. Audiences in Düsseldorf, Freyburg, San Diego, Utrecht, Colchester, Manchester, Münster, and Wuppertal also made a number of helpful suggestions for which I am very grateful. All bad ideas are mine.
} 
(2) $[\theta$ ai: $]$

\begin{tabular}{|c|c|c|c|c|c|}
\hline $\begin{array}{c}\text { NoComplex } \\
\text { ONSET }\end{array}$ & NoComplex & No & No & No & No \\
\hline \hline $\mathbf{R}$ & $\mathbf{R}$ & $\mathbf{R}$ & $\mathbf{R}$ & $\mathbf{R}$ & $\mathbf{R}$ \\
\hline
\end{tabular}

The distinctive constraint violations in 2 are desiderata for the surface form of three: a DESIDERATUM is a partial description of a surface structure in terms of markedness; a set of desiderata functions as the equivalent of an underlying form in standard generative phonology. In the case at hand the desiderata include the complexity of the onset and nucleus and the presence of the marked features [dental], [continuant], [retroflex], and [hi]; the desiderata do not contain any information about unmarked structure, for example, about the absence of a coda or the presence (rather than the complexity) of the onset and nucleus. Unmarked structure of this kind cannot be represented in terms of constraint violation because there are no constraints that it violates. The sound sequence that comes closest to these desiderata in English is [0.ii:]. Other possibilities either fail to manifest some of the desiderata or manifest nondesiderata: thus wreath [ui: $\theta$ ] has no violation of No COMPLEX ONSET, free [f.ji:] respects No

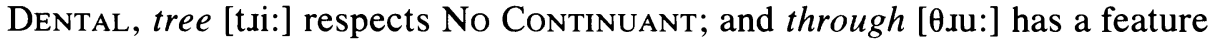
round which is not a desideratum for three.

The main difference between a set of desiderata and an autosegmental representation is ontological.: the former is a partial description of an object, the latter is the object described-2 describes 1 . Representation as pure markedness is thus a theory in which phonological representation consists of partial descriptions of surface objects given in terms of markedness violations. In this way desiderata conflate the representation and evaluation (markedness) of a form by describing it purely in terms of its marked features. Note that desiderata are not underlying forms in the traditional sense: they are partial descriptions of surface forms-direct OT has no underlying forms.

Representation as pure markedness (RPM) has a number of important results for grammatical theory. First, it requires abandoning a central (if bizarre) claim implicit in most current work in phonology, which I'll call the THEOREM OF IMPOSSIBILITY. Impossibility states that every underlying form is an impossible surface form; it keeps us from having a unified theory of representation. Impossibility follows jointly from the assumption that underlying forms are not syllabified and that surface forms are. I'll argue that impossibility is as theoretically and empiricially insupportable as it is counterintuitive. In its place RPM offers a completely unified theory of phonological representation throughout the grammar.

Second, RPM requires rather than stipulates the underspecification of phonological representations (Kiparsky 1982, Archangeli 1984, Steriade 1987). Unmarked structure is underspecified in direct OT because it cannot be represented as constraint violation. The permanence of underspecification (Steriade 1995) follows as well: unmarked structure is unspecified at all levels of phonology because it is not representable at any level. 
Third, RPM makes the linear order of segments fully redundant (cf. Cairns 1988). Linear representations like/pajama/ or [ba.na.na] are purely expository devices with RPM and play no role in either the representation or the evaluation of forms. Representation in direct OT keeps linearity to a bare minimum: in words like three it plays no distinctive role whatsoever.

Fourth, RPM is not statable in theories of phonology in which constraints are inviolable (Bird 1990, 1995, Goldsmith 1990, 1991, Lakoff 1993, Mohanan 1993, Paradis 1988, Scobbie 1991, 1992). RPM requires that constraints be violable because morphemes are represented solely by the constraints they violate. The only theory of phonology that presently uses violable constraints is optimality theory (Prince \& Smolensky 1993).

But RPM does not leave standard OT unchanged. The fifth major consequence of RPM is that it eliminates two of the five elements of standard OT (input and output strings) and diminishes the role of a third (GEN). Hence DIRECT OT. Where standard OT has unsyllabified segment strings (input), syllabified segment strings (output) and constraint violations (evaluation), direct OT has only constraint violations. One of the major roles of GEN, producing a candidate set of syllabified output parses for each unsyllabified input, is not needed. This reduction of theoretical machinery in OT is accomplished without adding anything to the model other than the notion of distinctive violation (RPM); aside from RPM, direct OT uses a proper subset of the machinery of standard OT. The resulting theory is formally simpler but capable of handling types of data that standard OT runs afoul of.

2. LeXICAL REPRESENTATION IN STANDARD OT. In practice, standard OT takes from previous work in generative phonology the idea that underlying forms (inputs) lack most of the prosodic structure that surface forms (outputs) have. The input for three consists of a string of three segments with no syllable or foot structure. A fully syllabified output string with onset $\left[\theta_{\mathrm{I}}\right]$ and nucleus [i:] comes about as the result of syllabifying the input string.

Such a view has some important implicit assumptions. Impossibility has already been mentioned: no input string is a possible output string, because inputs are stripped of prosody while outputs must be fully prosodified. This makes underlying representation necessarily unpronounceable, an unintuitive restriction at best. It also makes phonology necessarily derivational, since no input can surface without undergoing a process of syllabification. In this section I'll look at how this plays out in standard OT, but the bulk of the discussion holds for any theory in which underlying forms are not syllabified and surface forms are.

OPTIMALITY THEORY (OT) is a constraint-based theory of phonology that analyzes the phonologies of particular languages in terms of a single set of typologically well-founded well-formedness conditions. It incorporates markedness theory directly into phonological derivations in a computational component called EVAL, which allows only the least-marked structures to make it to the surface. Standard OT is based on three principles.

(3) Principles of optimality theory

a. Violability: constraints are violable, but violation is minimal. 
b. Ranking: constraints are ranked on a language-particular basis; the notion of minimal violation is defined in terms of this ranking.

c. Inclusiveness: the constraint hierarchy evaluates a set of candidate analyses that are admitted by very general considerations of structural well-formedness.

Nothing in 3 dictates the shapes of phonological representation, making the core of OT completely compatible with RPM. As we will now see, however, this is not the way in which standard OT has developed. Rather, OT analyses use prosodically deficient inputs and prosodically rich outputs, fully embracing impossibility. A brief overview of OT will make this clear. An OT grammar has five distinct components:

(4) Components of standard optimality theory

Inputs unsyllabified, unfooted strings of segments

Outputs syllabified, footed strings of segments

GEN a function taking one input to multiple outputs

Constraints a universal set of well-formedness conditions

Violations indicators of ill-formedness in terms of constraints

The role of each of these components may be illustrated in a constraint tableau (5), the central workplace of the theory, in which rich outputs are derived from impoverished inputs.

(5) An OT constraint tableau

\begin{tabular}{|c||c|c|}
\hline Input & CONSTRAINT & CONSTRAINT \\
\hline \hline Output $_{1}$ & & Violation \\
\hline Output $_{2}$ & Violation & \\
\hline
\end{tabular}

Inputs consisting of an unsyllabified string of segments may be realized as any of a large number of possible outputs (candidates), each of which contains the input in a fully prosodified form, with stress, syllables, feet, stray and epenthetic segments and so on present. This process of turning one input into multiple outputs is done by a general function GEN. The universal set of constraints is ranked on a language-particular basis and this ranking picks out one of the candidates as the best. This best or optimal candidate is the surface form in the language. In 5 the first candidate is optimal because it violates a less important (lower ranked) constraint than the second candidate violates. Neither candidate is perfectly well formed, but one is better formed than the other and that one is the output of the grammar.

Consider final devoicing in German. ${ }^{1}$ From the input /bund/ 'club' GEN produces a number of possible output candidates including [.bund.] and devoiced [.bunt.], where periods indicate syllable boundaries supplied by GEN. The role of EVAL is to pick out the grammatical candidate, in this case [.bunt.]. To do so, EVAL considers how well each surface candidate fares with respect to the

\footnotetext{
${ }^{1}$ See Vennemann 1972 and, for recent discussion, Wiese 1995.
} 
universal set of well-formedness constraints. Here the relevant constraints are Parse and No Voice Coda. Parse (Prince \& Smolensky 1993) requires all features of the input to be parsed into syllables-it is respected by [.bund.] and violated $(*)$ by [.bunt.] because the feature VOICE is not parsed into syllable structure (indicated by angle brackets around the feature).

(6) An OT constraint tableau

\begin{tabular}{|r||c|c|}
\hline \multicolumn{1}{|c||}{$/$ bund/ } & $\begin{array}{c}\text { NoVoICE } \\
\text { CODA }\end{array}$ & PARSE \\
\hline \hline bunt.<VOI> & & $*$ \\
\hline .bund. & $* !$ & \\
\hline
\end{tabular}

No Voice COda forbids voiced coda consonants-it is violated by [.bund.] and respected by [.bunt.]. Note that neither output candidate is well-formed in an absolute sense, since each violates a constraint. But one candidate is better formed, because German phonology ranks No VOICE CODA more highly than PARSE (ranking shown by the solid vertical line; unranked constraints are separated by a dotted line). Since [.bund.] violates the higher-ranked constraint, the devoiced candidate emerges as the output of the grammar.

Three additional elements in the tableau need to be mentioned here: the shading of the right-most column, the exclamation mark and the small hand pointing to the winning candidate. All are merely expository and play no role in the theory. Shading shows us where not to look-the column headed by No VoICE CODA is enough to pick a winner and the shaded column plays no role in the selection of the grammatical form in this tableau. The exclamation mark merely shows that a violation was fatal, that is, it removed a candidate from the running. The small hand points out the winner.

To see how impossibility arises in standard OT, consider the role played by GEN in the German case above. Many of the constraints used in OT evaluate candidates in terms of prosody: segments must belong to syllables (PARSE), syllables must have segments in them (FILL), must have onsets (ONSET) and must not have codas (No CODA); codas may not be voiced (No VoICE CODA), and so on. Because inputs in OT are devoid of prosody, they cannot be directly evaluated by such constraints: /bund/ does not violate No VOICE CODA because it has no coda, / $\theta$ ii:/ does not violate Complex ONS or CoMPLEX Nuc because it has no onset or nucleus. To make inputs susceptible to evaluation in terms of prosodic constraints GEN must syllabify them.

But if syllable structure is so central to evaluation in OT, why is it left out of underlying representation? Generative phonology has kept syllable structure out of underlying representation because syllable structure is generally not contrastive given a string of segments. Thus, as Blevins $(1995: 221)$ points out, minimal pairs like Ida [?áy.da] and $A \ddot{i d a}$ [?a.íy.da] are relatively rare. OT has probably kept syllable structure out of underlying representation for this reason. Interestingly, however, this sort of consideration is not binding in the theory of OT, which places no constraints whatsoever on the shapes of input forms. 
Rather, the shapes of inputs in OT are determined by the learning process: children posit those inputs that allow for the simplest derivations (cf. Chomsky 1993). The process is called LeXICON OPTIMIZATION by Prince and Smolensky (1993:192):

Suppose that several different inputs $I_{1}, I_{2}, \ldots, I_{n}$ when parsed by a grammar $G$ lead to corresponding outputs $\mathrm{O}_{1}, \mathrm{O}_{2}, \ldots, \mathrm{O}_{\mathrm{n}}$, all of which are realized as the same phonetic form $\Phi$-these inputs are all PHONETICALLY EQUIVALENT with respect to $G$. Now one of these outputs must be the most harmonic, by virtue of incurring the least significant violation marks: suppose this optimal one is labeled $\mathrm{O}_{\mathrm{k}}$. Then the learner should choose, as the underlying form for $\Phi$, the input $I_{k}$.

As Inkelas (1994) has recently shown, lexicon optimization actually requires that most prosodic structure be underlying. ${ }^{2}$ She shows that nonalternating structure is best put into inputs because this allows inputs and outputs to be maximally similar, making derivations maximally simple. Consider three: the syllable structure of the root is invariably CV, even if affixes (three-s, threeness) are added. Since any prosodic structure in the input that lacks a corresponding structure in the output violates constraints against adding structure, the language learner should select that input which already has the prosodic structure of the output form, including its syllable structure. Given lexicon optimization three must be learned as a one-syllable word. Compare the claim in Natural Generative Phonology that lexical representations of nonalternating parts of morphemes are identical to their phonetic representations; see Vennemann 1973.

The same argument can be made in terms of correspondence theory (McCarthy \& Prince 1995), according to which input and output forms are supposed to be maximally similar. Most work in correspondence theory has focused on segmental correspondence, the fact that the segmental string of one representation (the input) tends to correspond to that of another (the output) (Benua 1995, Gnanadesikan 1995, Lamontagne \& Rice 1995, McCarthy 1995, Pater 1995). But as McCarthy and Prince point out, "it is a straightforward matter to generalize the approach to higher-order units of prosodic structure such as moras, syllables, feet, heads of feet, as well as tones and even distinctive feature nodes, in support of theories of quantitative transfer, compensatory lengthening, and the effects of floating features' (1995:14).

We see then that impossibility is not a necessary consequence of standard OT. If lexicon optimization is taken to its logical conclusion, prosodic structure is relevant at all levels of phonological description. Indeed, standard OT requires both marked and unmarked nonalternating structure to be underlying (Inkelas 1994). Direct OT allows only a proper subset of this in desiderata because RPM can never represent unmarked structure, alternating or not. The desiderata of direct OT are thus necessarily leaner than the inputs of standard OT.

\footnotetext{
${ }^{2}$ See Cairns 1988, Coleman 1991, Dobrin 1993, Golston 1996, Golston \& van der Hulst 1996 for a range of additional arguments that prosodic structure is underlying.
} 
3. Lexical RePresentation in Direct OT. A syllable like fly [flai] is not perfect: the onset and nucleus are complex, the features involve some articulatory effort. All of this is the stuff of OT proper and it should now be clear that the constraint violations that are used to EVALUATE candidates can also be used to REPRESENT them. There is only one syllable in English that satisfies all and only the desiderata in 7 and that syllable is [flar].

(7) [flar]

\begin{tabular}{|c|c|c|c|c|c|c|}
\hline $\begin{array}{c}\text { NoCPLX } \\
\text { ONS }\end{array}$ & $\begin{array}{c}\text { NoCPLX } \\
\text { NuC }\end{array}$ & $\begin{array}{c}\text { No } \\
\text { LAB }\end{array}$ & $\begin{array}{c}\text { No } \\
\text { LAT }\end{array}$ & $\begin{array}{c}\text { No } \\
\text { CONT }\end{array}$ & $\begin{array}{c}\text { No } \\
\text { Lo }\end{array}$ & $\begin{array}{c}\text { No } \\
\text { HI }\end{array}$ \\
\hline \hline $\mathrm{R}$ & $\mathrm{R}$ & $\mathrm{R}$ & $\mathrm{R}$ & $\mathrm{R}$ & $\mathrm{R}$ & $\mathrm{R}$ \\
\hline
\end{tabular}

Thus we may use the evaluation of a surface form as a (partial) description of its phonological form. Desiderata encode what is distinctive (marked) about a string and render linear representation entirely superfluous.

3.1. Alignment. First we need a way of differentiating among syllables like cat [kæt], tack [tæk] and act [ækt] which are gesturally and prosodically identical. We may do so in terms of Alignment theory (McCarthy \& Prince 1993c), by recognizing that some of the distinctive features of a word are closer to the beginning of the word than others: in [kæt] the dorsal feature occurs at the beginning of the word while in [tæk] it is separated from it by the syllable peak [æ]. (Grammatical evidence for this type of alignment constraint is discussed below.)

It should now be clear how cat, tack and act can be distinguished. I define a constraint 8 that requires every feature $f$ to be word-initial and register violations of it with one asterisk per syllable peak that intervenes between that feature and the beginning of the word:

(8) ALIGN-L $(f, \mathrm{WD}) \quad$ (Every feature $f$ is word-initial)

Abbreviating this simply as Align- $f$ for the present, we may represent $c a t$ with a misaligned coronal feature (9): ${ }^{3}$

(9) $[\mathrm{k} æ \mathrm{t}]$

\begin{tabular}{|c|c|c|c|c|}
\hline $\begin{array}{c}\text { No } \\
\text { STOP }\end{array}$ & $\begin{array}{c}\text { ALIGN } \\
\text { COR }\end{array}$ & $\begin{array}{c}\text { No } \\
\text { DOR }\end{array}$ & $\begin{array}{c}\text { No } \\
\text { FRONT }\end{array}$ & $\begin{array}{c}\text { No } \\
\text { LO }\end{array}$ \\
\hline \hline RR & R & R & $R$ & $R$ \\
\hline
\end{tabular}

Ex. 9 describes a word with two stops (indicated by double violation of No STOP), one coronal and one dorsal; the coronal is misaligned from the beginning of the word by a syllable peak, the dorsal is not. This can only mean that the

\footnotetext{
${ }^{3}$ Here and elsewhere I will use different features for vowels (e.g. round) and consonants (e.g. labial) but nothing depends on this. Rounding in vowels could just as well be expressed by violation of No Round Nucleus, rounding in consonants by No Round MARGiN.
} 
dorsal is a word onset and that the coronal occurs later in the word: [kVt. . .]. There are also two vocalic features [front] and [lo], neither of which is misaligned from the beginning of the word by a syllable peak. This leaves us with [kæt]. Additional violations are redundant and have been omitted for simplicity: e.g., violation of No CoR is redundant given violation of ALIGN COR. In what follows I leave out redundant desiderata for clarity only-lexicon optimization requires that they be there.

The representation for tack is similar except that the misaligned place feature is dorsal rather than coronal (10).

(10) $[\mathrm{tæk}]$

\begin{tabular}{|c|c|c|c|c|}
\hline $\begin{array}{c}\text { NO } \\
\text { STOP }\end{array}$ & $\begin{array}{c}\text { No } \\
\text { COR }\end{array}$ & $\begin{array}{c}\text { ALIGN } \\
\text { DOR }\end{array}$ & $\begin{array}{c}\text { No } \\
\text { FRONT }\end{array}$ & $\begin{array}{c}\text { NO } \\
\text { LO }\end{array}$ \\
\hline \hline RR & $R$ & $R$ & $R$ & $R$ \\
\hline
\end{tabular}

Finally, we may represent act with a misaligned dorsal, a misaligned coronal and a missing onset (11).

(11) $[æ k t]$

\begin{tabular}{|c|c|c|c|c|c|}
\hline $\begin{array}{c}\text { No } \\
\text { STOP }\end{array}$ & $\begin{array}{c}\text { ALIGN } \\
\text { COR }\end{array}$ & $\begin{array}{c}\text { ALIGN } \\
\text { DOR }\end{array}$ & $\begin{array}{c}\text { No } \\
\text { FRONT }\end{array}$ & $\begin{array}{c}\text { No } \\
\text { LO }\end{array}$ & ONS \\
\hline \hline RR & $\mathrm{R}$ & $\mathrm{R}$ & $\mathrm{R}$ & $\mathrm{R}$ & $\mathrm{R}$ \\
\hline
\end{tabular}

These desiderata suffice to distinguish the phonological forms of cat, tack and act from one another and from all other morphemes in English.

Syllable peaks need not of course be vocalic. In burl [bill] the lateral feature for [1] is misaligned because of the peak [ł]. This misalignment is what distinguishes burl from blur [bly], in which no features are misaligned because no sounds occur after the syllable peak.

Looking now at the representation of a syllabically more complex form like stink, we see how efficient RPM can be (redundant violations omitted).

(12) $[$ stink]

\begin{tabular}{|c|c|c|c|c|c|}
\hline No & ALIGN & ALIGN & No & No & No \\
StOP & NAS & DOR & COR & CONT & HI \\
\hline \hline RR & $\mathrm{R}$ & $\mathrm{R}$ & $\mathrm{R}$ & $\mathrm{R}$ & $\mathrm{R}$ \\
\hline
\end{tabular}

Nothing further needs to be said about the linear order of any of the features because their order within onset, nucleus and coda is not distinctive but given by sonority sequencing (Fujimura \& Lovins 1978, Fujimura 1992).

We can now see how lexicon optimization works in direct OT: a morpheme's desiderata include all distinctive surface violations associated with it as well as any nonalternating violations, distinctive or not (see Inkelas 1994 and discussion above). Consider the forms in 13: 
(13) stink [stink] stink-s [stınk-s] stink-y [stın.k-i] stink-er [stin.k-I]

The nasal feature invariably surfaces in coda position; not so for the stop feature, which surfaces sometimes in the coda, sometimes in the onset of the following syllable. Given Inkelas's formulation of lexicon optimization, the desiderata for stink must include violation both of No NASAL CODA and of ALIGN NASAL.

Similarly for pairs such as English ax [æks] vs. ask [æsk]. The apparent [ks] vs. [sk] contrast in coda position is found only at morpheme-edge (Fudge 1969, Selkirk 1982) and has been taken as evidence for a special appendix position at the end of a word: $a x$ has an appendix [s] and ask does not. Sidestepping the appendix issue, we may distinguish these forms as follows:

(14) [æsk]

\begin{tabular}{|c|c|c|c|c|c|c|}
\hline $\begin{array}{c}\text { NoCont } \\
\text { CoDA }\end{array}$ & $\begin{array}{c}\text { NoCor } \\
\text { CODA }\end{array}$ & $\begin{array}{c}\text { AligN } \\
\text { StoP }\end{array}$ & $\begin{array}{c}\text { AligN } \\
\text { DOR }\end{array}$ & $\begin{array}{l}\text { No } \\
\text { Lo }\end{array}$ & $\begin{array}{c}\text { No } \\
\text { FRONT }\end{array}$ & ONS \\
\hline $\mathrm{R}$ & $\mathrm{R}$ & $\mathrm{R}$ & $\mathrm{R}$ & $\mathrm{R}$ & $\mathrm{R}$ & $\mathrm{R}$ \\
\hline
\end{tabular}

(15) $[æ k s]$

\begin{tabular}{|c|c|c|c|c|c|c|}
\hline $\begin{array}{c}\text { NoStOP } \\
\text { CODA }\end{array}$ & $\begin{array}{c}\text { NoDOR } \\
\text { CODA }\end{array}$ & CONT & COR & Lo & FRONT & ONS \\
\hline \hline $\mathrm{R}$ & $\mathrm{R}$ & $\mathrm{R}$ & $\mathrm{R}$ & $\mathrm{R}$ & $\mathrm{R}$ & $\mathrm{R}$ \\
\hline
\end{tabular}

The desiderata for ask include the [s] coda that all forms of the word have: ask [æsk], asks [æsks], asking [æs.kın]; those for ax include the invariant [k] coda found in ax [æks], axes [æk.siz], axing [æk.sın].

Polysyllabic forms differ from monosyllabic forms in that they have misaligned vocalic features. Consider desiderata for prosodically and gesturally identical names like Gino [\$irno] and Joni [\$o:ni].

(16) [\$zi:no]

\begin{tabular}{|c|c|c|c|c|c|c|c|}
\hline $\begin{array}{l}\text { ALIGN } \\
\text { RD }\end{array}$ & $\begin{array}{l}\mathrm{No} \\
\mathrm{HI}\end{array}$ & $\begin{array}{c}\text { NoCPlX } \\
\text { NuC }\end{array}$ & $\begin{array}{c}\text { No } \\
\text { STOP }\end{array}$ & $\begin{array}{l}\text { No } \\
\text { PAL }\end{array}$ & $\begin{array}{l}\text { No } \\
\text { VoI }\end{array}$ & $\begin{array}{l}\text { AligN } \\
\text { NAS }\end{array}$ & $\begin{array}{c}\text { ALIGN } \\
\text { COR }\end{array}$ \\
\hline $\mathrm{R}$ & $\mathrm{R}$ & $\mathrm{R}$ & $\mathrm{R}$ & $\mathrm{R}$ & $\mathrm{R}$ & $\mathrm{R}$ & $\mathrm{R}$ \\
\hline
\end{tabular}

(17) [\$o:ni]

\begin{tabular}{|c|ccc|c|c|c|c|c|}
\hline No & ALIGN & NoCPLX & No & No & No & ALIGN & ALIGN \\
RD & HI & NUC & STOP & PAL & VoI & NAS & COR \\
\hline \hline $\mathrm{R}$ & $\mathrm{R}$ & $\mathrm{R}$ & $\mathrm{R}$ & $\mathrm{R}$ & $\mathrm{R}$ & $\mathrm{R}$ & $\mathrm{R}$ \\
\hline
\end{tabular}


The difference occurs in the first two columns; the forms are otherwise identical.

Similar pairs may be found with consonants. Compare English Akbar and Apgar 'type of test for newborns'. The desiderata are identical except that Akbar distinctively violates No Dorsal CoDA while Apgar violates No LABIAL CODA (omitting vowel desiderata for simplicity).

(18) [ækbar]

\begin{tabular}{|c|c|c|c|c|c|c|c|c|}
\hline $\begin{array}{c}\text { NoDOR } \\
\text { CODA }\end{array}$ & $\begin{array}{c}\text { ALIGN } \\
\text { DOR }\end{array}$ & $\begin{array}{c}\text { ALIGN } \\
\text { LAB }\end{array}$ & $\begin{array}{c}\text { ALIGN } \\
\text { STOP }\end{array}$ & $\begin{array}{c}\text { ALIGN } \\
\text { VOI }\end{array}$ & $\begin{array}{c}\text { ALIGN } \\
\text { RETR }\end{array}$ & $\begin{array}{c}\text { No } \\
\text { RETR }\end{array}$ & ONS \\
\hline \hline $\mathrm{R}$ & $\mathrm{R}$ & $\mathrm{R}$ & $\mathrm{R}$ & $\mathrm{R}$ & $\mathrm{RR}$ & $\mathrm{R}$ & $\mathrm{R}$ \\
\hline
\end{tabular}

(19) [æpgar]

\begin{tabular}{|c|c|c|c|c|c|c|c|}
\hline $\begin{array}{c}\text { NoLAB } \\
\text { CODA }\end{array}$ & ALIGN & Allign & ALIGN & ALIGN & ALIGN & No & ONS \\
\hline \hline $\mathrm{R}$ & $\mathrm{R}$ & $\mathrm{R}$ & $\mathrm{R}$ & $\mathrm{R}$ & $\mathrm{RR}$ & $\mathrm{R}$ & $\mathrm{R}$ \\
\hline
\end{tabular}

Again, the difference is in the first column, the desiderata being otherwise identical.

The double alignment violations (RR) in 18 and 19 require some explanation. They can mean either that there is one instance of $f$ which is two peaks from the beginning of the word or that there are two instances of $f$, each of which is one peak from the beginning of the word. What disambiguates them is the number of No $f$ violations. In Akbar and Apgar there is a single violation of No Retroflex and the double violation of ALIGN RETroflex indicates one feature two peaks from the beginning of the word. A case of two identical features both of which are one peak from the beginning is found in a word like Northrop; here the double violation of ALIGN RETROFLEX must be distributed over the two occurrences of the feature. Potential ambiguities like this are always resolved by other desiderata.

The plausibility of using featural alignment constraints in desiderata rests of course with the independent need for such constraints in grammar. There is evidence for three types of featural alignment: tonal, vocalic, and consonantal. (For evidence for alignment constraints in general see McCarthy \& Prince 1993c.)

Autosegmental studies of tone (Leben 1973, Goldsmith 1979, Pulleyblank 1986) have shown that tonal melodies in many languages are mapped onto tone-bearing units (TBUs) directionally, usually from left to right. Thus a tonal melody LH surfaces as LHH on a three-syllable word (20a), with one-to-one association of tones to TBUs and spread of $\mathrm{H}$ to the final TBU. A tonal melody $\mathrm{HL}$, on the other hand, surfaces as HLL (20b).

(20) Tonal alignment
a. LH melody
$\sigma \sigma \sigma$
I
$\mathrm{L} \mathrm{H}$
b. HL melody

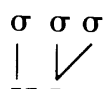
H L 
Translating this into alignment terms, we see that the tones are all as far to the left as they can be without violating the ban on contour tones. In $20 \mathrm{a}$ the $\mathrm{L}$ is properly aligned and the $\mathrm{H}$ is misaligned by a single syllable; were $20 \mathrm{a}$ to be realized as $L L H$, the $\mathrm{L}$ would still be properly aligned but the $\mathrm{H}$ would be misaligned by two syllables.

Evidence for alignment of vocalic features is found in several languages such as Tiv (Pulleyblank 1988, Archangeli \& Pulleyblank 1994). In Tiv verbal roots 'no features are actually assigned to vowels underlyingly; surface forms result from the interaction of morpheme-level specifications with rules of spreading and redundancy' (Pulleyblank 1988:299). Vowel features are mapped onto syllables from left to right, with the result that the underspecified vowel [e] generally occurs only after other vowels; conversely, high vowels do not occur after nonhigh vowels, round vowels do not occur after nonround vowels, and low vowels do not occur after non-low vowels. Again, this translates into alignment constraints that require vocalic features to align with the beginnings of verbal roots. A few exceptional cases violate these constraints: e.g. dzènda 'drive away' is one of four verbal roots that violates ALIGN-Low.

Similar cases are found in other languages. ${ }^{4}$ In the Altaic languages Vogul (Kálmán 1965), Bashkir (Poppe 1962) and Ostyak (Trubetzkoy 1939) round vowels only occur word-initially, indicating that ALIGN Round is always respected and that ROUND is never multiply linked (SPREAD in the language of another day). In Yokuts a vowel is round only if every vowel to its left is also round (Newman 1944, Steriade 1979, Archangeli 1984), indicating that ALIGN Round is never violated although it may be multiply linked. Hungarian provides evidence for ALIGN BACK: in (native) stems a vowel is back only if every vowel to its left is back (Vago 1980:244ff.).

Evidence for the alignment of consonantal features comes from McCarthy's (1979) work on Classical Arabic. Greenberg (1960) observed that Classical Arabic had no roots of the shape X-X-Y; McCarthy explained this in terms of leftto-right association of melody to skeletal slots, in conjunction with an OCPdriven ban on adjacent identical autosegments. An alignment constraint requiring consonantal features to be root-initial has the same effect in a nonderivational theory. Given features defining two consonants [s] and [m], sasam is worse than samam because in sasam the features NASAL and LABIAL are further removed from the beginning of the word.

(21) Consonantal alignment
a. [samam]
CVCVC
cont nas
cor lab
b. ${ }^{*}[$ sasam $]$
CVCVC

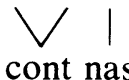
cor lab

The form in $21 \mathrm{~b}$ would be preferred if alignment were defined in terms of the end of the word rather than the beginning. Evidence for right-align languages such as this will be given in \$4.1-4.2.

\footnotetext{
${ }^{4}$ This section draws heavily on the discussion of licensing in Steriade 1995:158ff.
} 
3.2. Faithfulness. The phonology of a language does not always permit morphemes to surface unchanged; following Prince \& Smolensky 1993 we may refer to such changes as FAITHFULNESS VIOLATIONS. In this section I show how breaches of faithfulness are handled within direct OT: little changes from standard OT except for the manner in which faithfulness violations are represented. In standard OT faithfulness is violated whenever the input and the output are different; in direct OT a violation occurs whenever the desiderata and the output are different. In either case, violations of faithfulness are induced by the phonological system of the language at hand.

Faithfulness violations may take one of two forms: the output may fail to manifest all of the desiderata of a morpheme (e.g. deletion) or it may manifest constraint violations that are not desiderata (e.g. epenthesis). The former case is schematized in 22 .

(22) Nonrealization of desiderata

\begin{tabular}{|c|c|}
\hline CONSTRAINT & realized as \\
\hline & $\mathrm{R}$ \\
\hline & \\
\hline
\end{tabular}

Final devoicing, already discussed, is a good case of desiderata not being realized in the output. The desiderata for German Bund 'club' include violation of No VoI and of ALIGN VoI for the final consonant [d]; but neither desideratum is realized in the winning candidate because the language does not allow voiced codas. As in the standard OT analysis, faithfulness is violated here to comply with a general constraint of the language. Ex. 23 shows this in tabular form with two obvious candidates for Bund: the first is unfaithful $(\langle\mathrm{R}\rangle)$ but is the winning candidate nonetheless because the second candidate (which is faithful) fatally violates $(* !)$ No VoICE CODA.

(23) Final devoicing

\begin{tabular}{|r||c|c|c|c|c:c:c:c|}
\hline & $\begin{array}{c}\text { NOVOI } \\
\text { CODA }\end{array}$ & $\begin{array}{c}\text { ALIGN } \\
\text { VOI }\end{array}$ & $\begin{array}{c}\text { ALIGN } \\
\text { COR }\end{array}$ & $\begin{array}{c}\text { ALIGN } \\
\text { NAS }\end{array}$ & $\begin{array}{c}\text { No } \\
\text { LAB }\end{array}$ & $\begin{array}{c}\text { No } \\
\text { VoI }\end{array}$ & $\begin{array}{c}\text { No } \\
\text { RD }\end{array}$ & $\begin{array}{c}\text { Ho } \\
\text { HI }\end{array}$ \\
\hline \hline bunt.<VOI> & & $<\mathbf{R}>$ & $\mathbf{R}$ & $\mathbf{R}$ & $\mathbf{R}$ & $\mathbf{R}$ & $\mathbf{R}$ & $\mathbf{R}$ \\
\hline bund. & $* !$ & $\mathbf{R}$ & $\mathbf{R}$ & $\mathbf{R}$ & $\mathbf{R}$ & $\mathbf{R}$ & $\mathbf{R}$ & $\mathbf{R}$ \\
\hline
\end{tabular}

For cases such as these deletion wins the day, and the grammatical output has unrealized desiderata $(\langle\mathrm{R}\rangle)$. Direct OT treats alternation just like standard phonology does, as the result of realizing a morpheme in a given phonological system. Every desideratum is realized unless something in the grammar prevents it.

Violations of faithfulness may also involve the addition of marked structure by the phonology, as schematized in (24).

(24) Realization of nondesiderata

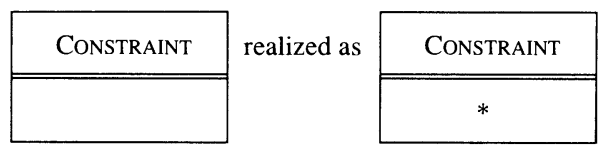


Epenthesis is a clear case of this and involves violation of the constraint FILL SYllable. Consider the epenthesis in English hisses [hI.s-ə-z], from $/ \mathrm{his} / \mathrm{and} / \mathrm{z} /$ (25). To keep morphological affiliation of desiderata clear, I use $\mathrm{R}$ for violations distinctive of the root and $\mathrm{A}$ for violations distinctive of the affix.

(25) $[$ hisəz]

\begin{tabular}{|c|c|c|c|c|c|c|c|c|}
\hline & ОсP & $\begin{array}{c}\text { No } \\
\text { CONT }\end{array}$ & $\begin{array}{l}\text { No } \\
\text { VoI }\end{array}$ & $\begin{array}{c}\text { ALIGN } \\
\text { CONT }\end{array}$ & $\begin{array}{c}\text { ALIGN } \\
\text { COR }\end{array}$ & $\begin{array}{l}\text { No } \\
\text { S.G. }\end{array}$ & $\begin{array}{l}\text { No } \\
\mathrm{HI}\end{array}$ & $\begin{array}{l}\text { FILL } \\
\text { SYLL }\end{array}$ \\
\hline W hI.s-ว-Z & & $\mathrm{RA}$ & A & $\mathrm{R}$ & $\mathrm{R}$ & $\mathrm{R}$ & $\mathrm{R}$ & * \\
\hline his- $<\mathrm{z}>$ & & $\mathrm{R}<\mathrm{A}>$ ! & $\langle A\rangle$ & $\mathrm{R}$ & $\mathrm{R}$ & $\mathrm{R}$ & $\mathrm{R}$ & \\
\hline $\mathrm{h} \mathrm{I}<\mathrm{s}>-\mathrm{Z}$ & & $<\mathrm{R}>$ !A & A & $<\mathrm{R}>$ & $<\mathrm{R}>$ & $\mathrm{R}$ & $\mathrm{R}$ & \\
\hline his-z & $* !$ & RA & A & $\mathbf{R}$ & $\mathbf{R}$ & $\mathbf{R}$ & $\mathbf{R}$ & \\
\hline
\end{tabular}

The first candidate has an epenthetic vowel in violation of low-ranked FILL Syllable, but respects every desideratum of the root. The second fails because it is unfaithful to the affix (doesn't have the $[\mathrm{z}]$ ), the third because it is unfaithful to the root (doesn't have the [s]). The final candidate fails despite its faithfulness because it contains an impossible sequence [sz] in violation of the OCP (Leben 1973). As in standard OT, epenthesis is the phonology's response to the shape of the morphemes that are brought together.

Faithfulness in direct OT, then, is much the same as in the standard theory. Candidates are evaluated on the basis of faithfulness (whether every desideratum appears in the output) and on the basis of general well-formedness principles (whether constraints are violated). Direct OT is merely standard OT with a restrictive theory of representation.

3.3. Discussion. RPM works because there is a general equivalence between a prosodified representation on the one hand and a set of constraint violations on the other. A simple Gedankenexperiment makes this clear: imagine two minimally distinct candidates, A and B, only one of which is grammatical in the language at hand. If standard OT can rank A and B with respect to each other (and it must if only one of them is grammatical), there must be some nonempty set of constraints $\mathrm{C}$ that $\mathrm{A}$ and $\mathrm{B}$ violate to different degrees. Then the violations in $C$ can distinguish any two underlying representations $\alpha$ and $\beta$, where $\alpha$ has the same shape as $A$ and $\beta$ has that of $B$.

That is, standard OT assumes already that any phonologically relevant distinction can be expressed in terms of violations of one or more constraints. Direct OT uses this necessary assumption to cut some of the fat (UR and SR segment strings) out of the theory by representing morphemes DIRECTLY by the constraints they violate at surface structure. Constraint violations are the distinctive features of direct OT, they represent all phonologically and morphologically relevant contrasts. Segment strings are mere expository devices in direct OT, akin to shaded cells, exclamation marks and the pointing hand.

The upshot of RPM is that representation and evaluation are cut from the same cloth, the cloth of evaluation. Given the rich evaluative component of standard OT there is simply no need for string-based representation. Nor is 
syllabification required to get from input to an evaluable candidate; a significant part of the work done by GEN in the standard theory is thus not required in direct OT. Desiderata and output are the same types of formal object: impossibility does not arise under RPM. This is good because impossibility is not a fact about language but a choice on the part of linguists to insist on a certain type of representation at the expense of lengthy derivations. If we value shortness of derivation instead (Chomsky 1993), we arrive at a different type of grammar in which impossibility does not arise.

4. Problematic morphology. We have seen that it is possible to represent strings of segments in terms of distinctive constraint violations or desiderata. In this section I show that RPM generalizes naturally to prefixes and suffixes $(\S 4.1)$, infixes $(\S 4.2)$, and circumfixes $(\S 4.3)$, as well as to zero morphology (\$4.4), subtractive morphology (\$4.5), reduplication (\$4.6) and templatic morphology (\$4.7). Thus the central claim of direct OT, that morphemes are represented by the constraints they violate on the surface, generalizes to all types of morphology. There is no morpheme whose representation and evaluation are distinct. RPM represents things directly in terms of observable surface patterns. Most roots and affixes are represented purely in terms of Nof and ALIGN $f$ violations. We will now see how this strategy generalizes to other types of morphology: prefixation distinctively violates Alignment; infixation and circumfixation distinctively violate ConTIGUITY; subtractive morphology distinctively violates PARSE; reduplication distinctively violates FiLL; and so on.

4.1. AfFiXes. Affixation is generally not considered a difficult morphological process, but it does cause problems in standard OT because it requires languagespecific constraints, something not otherwise tolerated in the theory (Prince \& Smolensky 1993). Let me illustrate with McCarthy and Prince's (1993c) treatment of Tagalog um-. They claim that the prefix is placed before its host so as not to violate a constraint which demands that it be there. More precisely, they claim that the alignment constraint in 26 is responsible for prefixation of $u m-$ :

(26) Align-um

$$
\text { Align ([um] }]_{\text {Af }}, \mathrm{L}, \text { Stem, L) }
$$

(The constraint applies similarly for suffixes, with $R$ instead of $L$ ). This constraint is a very unlikely candidate for a linguistic universal. ${ }^{5}$ Noting, as McCarthy and Prince do, that part of the constraint (ALIGN) is universal and that only the argument it takes $(u m)$ is language specific does not make the constraint any less tied to Tagalog. Moreover, 26 misses an important generalization about Tagalog: prefixing is the norm, not the exception in Tagalog (Schachter \& Otanes 1972, Lieber 1992).

Direct OT avoids both of these problems. First, the generalization problem. In a predominantly prefixing language like Tagalog, I postulate that the featural signature of a morpheme is given though violation of ALIGN-R $(f, W D)$, rather

\footnotetext{
${ }^{5}$ Elsewhere, McCarthy and Prince (1993b:10) formalize the constraint as 'EDGEMOst (L, $\mathrm{um}$ ): The morpheme $u m$ is located at the left edge, is a prefix.' Again, the constraint is language-specific.
} 
than Align-L ( $f$, WORD): features are aligned to the end of the word rather than the beginning. This is why Tagalog is overwhelmingly prefixing: if the distinctive features in a stem are to be word-final, affixes must occur at the beginning of the word. The desiderata of Tagalog aral 'teach' are given below. I assume that [r] and [1] share a spread feature LIQUID and that [1] is also LATERAL; likewise, I assume that there is only one Lo feature spread over both instances of [a], and that it is properly aligned. ${ }^{6}$

(27) [aral]

\begin{tabular}{|c|cc|c|}
\hline $\begin{array}{c}\text { SPREAD } \\
\text { LO }\end{array}$ & No & $\begin{array}{c}\text { SPREAD } \\
\text { LIQ }\end{array}$ \\
\hline \hline $\mathrm{R}$ & LAT & $\mathrm{R}$ & $\mathrm{R}$ \\
\hline
\end{tabular}

The desiderata of the affix $\mathrm{um}$ include no distinctive misalignment because neither the consonantal nor the vocalic features are separated from the end of the word by a syllable peak. ${ }^{7}$

(28) [um]

\begin{tabular}{|c|c|c|}
\hline $\begin{array}{c}\text { No } \\
\mathrm{HI}\end{array}$ & $\begin{array}{c}\text { No } \\
\text { RD }\end{array}$ & $\begin{array}{c}\text { No } \\
\text { LAB }\end{array}$ \\
\hline \hline $\mathrm{A}$ & $\mathrm{A}$ & $\mathrm{A}$ \\
\hline
\end{tabular}

Affixation leads to constraint conflict because both the features of the root and those of the affix want to be word-final. Following McCarthy \& Prince 1994, I assume that faithfulness to roots is universally more highly ranked than faithfulness to affixes:

(29) FAITH $_{\text {ROOT }} \gg$ FAITH $_{\text {AFFIX }}$

This means that um must surface as a prefix, in deference to the root.

Consider now a tableau. We need only consider the alignment of the $[r]$ in the root to see that 29 guarantees prefixation. Candidate one (um-aral) allows complete faithfulness to the desiderata of the root: every feature of the root is perfectly aligned (see n. 6). Candidate two has a fatal extra coda consonant $[\mathrm{m}]$; candidates three, four and five misalign $[\mathrm{r}]$.

${ }^{6}$ That is, I assume an autosegmental representation like the following:

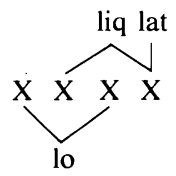

${ }^{7}$ Ex. 28 is not realized as [mu] in Tagalog because the features of [m] would then be misaligned from the end of the word by the syllable peak [u]. In a language that aligns features to the beginning of the word 28 would of course be realized as [mu] to avoid misalignment of [m]. 
(30) prefixation in Tagalog

\begin{tabular}{|c||c|c|}
\hline & $\begin{array}{c}\text { No } \\
\text { CODA }\end{array}$ & $\begin{array}{c}\text { ALIGN-R } \\
\text { LiQ }\end{array}$ \\
\hline \hline u.m-a.ral & $*$ & \\
\hline a.-um.-ral & $* * !$ & \\
\hline a.r-u.m-al & $*$ & $* !$ \\
\hline a.ra.-u.m-l & $*$ & $* !$ \\
\hline a.ra.-l-um & $*$ & $* !$ \\
\hline
\end{tabular}

Given RPM's method of encoding the order of distinctive features, there is no need for an ad hoc constraint like ALIGN ([um] $]_{\text {Af }}, \mathrm{L}$, STEM, L). The ordering of root and affix follows from general principle 29 and from the desiderata of the items in question.

The situation is slightly different for consonant-initial stems like gradwet 'graduate'. Suffixation (gradwet-um) is ruled out as before, but now prefixation (um-gradwet) is ruled out by No CODA, as demonstrated in Prince \& Smolensky 1993. Candidates one and two in 31 contain too many coda consonants; candidates four, five, and six fatally misalign the feature Lo of the first stem-vowel [a].

(31) infixation in Tagalog

\begin{tabular}{|r||c|c|}
\hline & $\begin{array}{c}\text { No } \\
\text { CODA }\end{array}$ & $\begin{array}{c}\text { ALIGN-R } \\
\text { Lo }\end{array}$ \\
\hline \hline um.-grad.wet & $* * * !$ & $\mathbf{R}$ \\
\hline g-um.-rad.wet & $* * * !$ & $\mathbf{R}$ \\
\hline gr-u.m-ad.wet & $* *$ & $\mathrm{R}$ \\
\hline gra.d-um.-wet & $* *$ & $\mathrm{R} * !$ \\
\hline grad.w-u.m-et & $* *$ & $\mathrm{R} * !$ \\
\hline grad.we.t-um & $* *$ & $\mathrm{R} * !$ \\
\hline
\end{tabular}

The winning candidate has everything in the root properly (mis)aligned and as few coda consonants as possible given the circumstances.

In the unmarked case (prefixes in a prefix-dominant language, suffixes in a suffix-dominant language), the order of affix and stem need not be represented in direct OT-precisely because the unmarked case can never be represented as a violation of markedness. To complete the picture we need to consider the marked cases-suffixes in a prefix-dominant language like Tagalog and prefixes in a suffix-dominant language like English. What is distinctive about such affixes on the surface is that they misalign the stems they attach to. RPM uses this distinctive violation as a desideratum, as that part of the underlying form of 
the affix which indicates its exceptional affixal status. The relevant desideratum for a suffix in Tagalog is violation of highly ranked ALIGN-R (STEM, WD), abbreviable as 32. For a prefix in English the desideratum is a violation of 33, ALIGNL (STEM, WD).

(32) suffix in a prefix-dominant language

(33) prefix in a suffix-dominant language
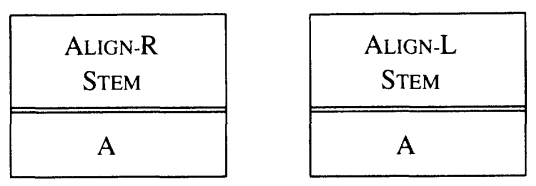

Note that these desiderata are exocentric-they are distinctive for the affix but take the stem as argument: a marked affix is one which misaligns stems. Given RPM, affixation does not require language specific or morpheme specific constraints of any sort. It requires only universal alignment constraints (already part of OT) and the possibility of distinctive violation (RPM) of these constraints by specific morphemes.

4.2. INFIXES. A major result of Optimality Theory is its insightful handling of pseudo-infixes, prefixes, or suffixes that are infixed under special circumstances. Pseudo-infixes are of two types. Tagalog um-infixation is driven by prosodic well-formedness (Prince \& Smolensky 1993): a prefix is infixed into C-initial stems ( $g r$-um-adwet) to avoid needless violation of No CoDA. We might call this PROSODICALLY INDUCED INFIXATION, due to basic constraints on syllable structure. We may contrast this with MORPHOLOGICALLY INDUCED INFIXATION, a case of which is found in Dakota (Moravcsik 1977). Dakota has two sets of stems, a prefixing set and an infixing set. An example of the latter is the stem lak'ota 'be a Lakota', which infixes pronominal markers in words like la-ma$k$ 'ota 'I am a Lakota'. The same affix occurs as prefix when it is attached to prefixing stems. The $\mathrm{CV}$ shape of the infix makes it clear that it is not infixed for prosodic reasons: *malak'ota and lamak'ota have identical syllable structure, showing that infixation is not driven here by prosody. (Dakota will be treated below; the desideratum for infixing stems is distinctive violation of CONTIGUITY (STEM), which bans discontinuous stems.)

But not all infixation is pseudo-infixation. This is most clear when infixation does not alternate with prefixation or suffixation and is detrimental to the wellformedness of a word. English expletive-infixation (Siegel 1974, Aronoff 1976, McCarthy 1982) is a good example: fan-fuckin-tastic, Ala-fuckin-bama, Mononga-fuckin-hela. As all of these cases make clear, expletive infixation invariably has detrimental effects. Most obviously, all cases of infixation have Contiguity (McCarthy \& Prince 1993b) violations that prefixed and suffixed words avoid. In addition, a word like Ala-fuckin-bama violates No CODA and ONSET but is not for that reason realized as fuckin-Alabama which violates neither. Thus it is not the case that fuckin is a prefix or suffix that is infixed because of its shape. 
But neither can infixation here be morphologically induced by the stem. Words like hyper-fantastic, $\left({ }^{*}\right.$ fan-hyper-tastic $)$, pro-Alabama $\left({ }^{*}\right.$ Ala-pro-bama) and anti-Monongahela $\left({ }^{*}\right.$ Mononga-anti-hela) show that none of these roots has a high ranking Align (RoOT, L, PRWD,L) requirement that forces infixation. The facts here support the native-speaker intuition that fuckin is inherently infixal-its status as such is not reducible to phonological details of its shape or to morphological requirements of its host.

Direct OT allows us to characterize true infixation as a violation of CONTIGUITY, its most salient surface cue. The relevant portion of the underlying form for fuckin is then:

(34) English expletive infix

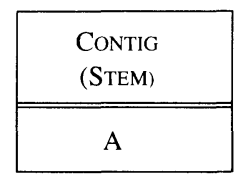

As with the treatment of prefixes, the violation here is exocentric: it is a distinctive feature of the affix but takes a stem as its argument. It straightforwardly captures what is distinctive about Califuckinfornia on the surface-the interruption of the stem by the affix. Here as elsewhere in direct OT, the violations that a morpheme brings with it are sufficient to represent it.

To complete the analysis we need to deal with positioning. According to McCarthy (1982), fuckin precedes the first noninitial foot of the word. Interestingly, this is exactly the position in which we tend to get unfooted syllables in English. As McCarthy \& Prince (1993c:79) point out, the normal right-to-left alternation of stress in English is interrupted word-initially.

(35) (Tàta) ma (góuchee) *Ta (táma) (góuchee)

They derive this fact from the interaction of two constraints: one that requires all prosodic words to begin with feet, ALIGN-L (WD, FT), the other that requires all feet to occur at the end of the word, ALIGN-R (FT, WD). These two constraints, then, define a natural break in an English word before the first noninitial foot (foot boundaries shown with parentheses); infixation occurs here because of these constraints and the underlying violation of ConTIGUiTY.

(36) Expletive infixation: Tatamafuckingouchee

\begin{tabular}{|r||c|c|c|}
\hline & $\begin{array}{c}\text { CONTIG } \\
\text { (STEM) }\end{array}$ & $\begin{array}{c}\text { ALIGN-L } \\
\text { (WD,FT) }\end{array}$ & $\begin{array}{c}\text { ALIGN-R } \\
\text { (FT.WD) }\end{array}$ \\
\hline \hline (fúckin)-Ta(táma)(góuchee) & $<\mathrm{A}>!$ & $*$ & $* *$ \\
\hline Ta-(fúckin)-(táma)(góuchee) & $\mathrm{A}$ & $* !$ & $* *$ \\
\hline (Táta)-(fúckin)-ma(gouchee) & $\mathrm{A}$ & & $* * * * * * * !$ \\
\hline \multirow{2}{*}{ (Táta)ma-(fúckin)-(gouchee) } & $\mathrm{A}$ & & $* * * * * * *$ \\
\hline (Táta)ma-(gou)(fúckin)-(chee) & $\mathrm{A}$ & & $* * * * * * * * * !$ \\
\hline (Táta)ma-(gouchee)-(fúckin) & $<\mathrm{A}>!$ & & $* * * * * *$ \\
\hline
\end{tabular}


As in standard OT, exact positioning of the infix within the stem is forced by other constraints; what direct OT allows here is some way to force infixation when it is not a phonological property of the affix or a morphological property of the stem.

We are now in a position to see how the relevant parts of the grammars of Tagalog, English, and Dakota differ. Tagalog ranks ConTiguiTy below No CoDA, with the result that infixes arise only under pressure from prosody. English ranks ConTIguiTy higher, with the result that it takes a distinctive violation of it (part of the desiderata of fuckin) to yield an infix. Dakota is like English, but what distinctively violates ConTIGUITY is the stem rather than the affix. The typology of infixation is thus neatly filled out: it may be prosodically driven (Tagalog) in which case infixation is driven by the shape of affix and stem; affix-driven (English) in which case you must simply know whether an affix is infixed or not; or stem-driven (Dakota), in which case you must know whether a stem is infixing or not.

Note that there is no parallel in standard OT for a distinctive violation of Contiguity. Thus for Dakota, McCarthy and Prince (1993c:113) cannot use the type of analysis I have sketched here. Rather they are forced to posit two distinct grammars for Dakota: an infixing grammar for infixing stems and a prefixing grammar for the rest. The infixing grammar values left-aligning roots more highly than left-aligning prefixes. Prefixing stems are subject to a grammar with the opposite ranking. A parallel analysis of English expletive infixation would seem to require that affixes likewise be able to induce different grammars. Grammar proliferation of this sort explains nothing (Inkelas et al. 1994) and represents a major weakening of OT, which is generally predicated on a single grammar (constraint ranking) per language.

The analysis sketched here makes use of the fact that some morphemes always violate ConTIGUITY by making this violation distinctive. Analyses of Dakota and English are possible without any proliferation of grammars: infixing stems (Dakota) and affixes (English) carry with them a violation of ConTIGUITY, prefixing stems (Dakota) and prefixes (English) do not.

4.3. Circumfixes. ${ }^{8}$ A number of languages have discontinuous affixes that both precede and follow the stem to which they attach (Bauer 1988). In terms

\footnotetext{
${ }^{8}$ The existence of circumfixes is disputed. Lieber (1981), Scalise (1984), Corbin (1987) and Schultink (1987), among others, claim that circumfixes are combinations of suffixation with independent prefixation. But Bauer (1988), Anderson (1992) and ten Hacken (1994) have argued for the existence of circumfixes on the basis of subcategorization mismatches. The Dutch formative in gebergte 'group of mountains, mountain range', for instance seems to consist of berg 'mountain', the suffix -te and the prefix ge-. But as ten Hacken (1994:214) points out,

The suffix -te exists, e.g. diepte ('depth') from diep ('deep'), but it attaches only to adjectives and produces a noun. The prefix ge- exists as well, e.g. gelach ('laughter') from ('laugh'), but it only attaches to verbs, yielding a noun. Since berg is a noun, neither ge-nor - $t e$ can attach to it to produce one of the intermediate forms * $g e b e r g$ or *bergte. Therefore, these intermediate forms are not possible words, and ge-te must be analyzed as a 'circumfix' in the terminology of Bauer (1988).

I find the argument compelling but will not pursue the issue further as it falls beyond the scope of this paper. Suffice it to say that if there are circumfixes, they are best described as they are in the following section.
} 
of the output, circumfixation is to affixes what infixation is to stems, a blatant violation of CONTIGUITY. With infixes the violation is exocentric, realized as a discontinuous stem; with circumfixes the contiguity violation is endocentric, realized as a discontinuous affix.

Consider the Tagalog data in 37, from Schachter \& Otanes 1972; 38 represents the circumfix.

(37) $k a$. . . an 'the class or group of $\mathrm{x}^{\prime}$

$\begin{array}{llll}\text { ka-bukir-an } & \text { 'fields' } & \text { bukid } & \text { 'field' } \\ \text { ka-bunduk-an } & \text { 'mountains' } & \text { bunduk } & \text { 'mountain' } \\ \text { ka-tagalug-an } & \text { 'the Tagalogs' } & \text { Tagalog } & \text { 'a Tagalog' } \\ \text { [ka] ... . [an] } & & & \end{array}$

\begin{tabular}{|c|c|c|c|c|c|}
\hline $\begin{array}{c}\text { ConTIG } \\
\text { (AfFIX) }\end{array}$ & $\begin{array}{c}\text { LLIGN-R } \\
\text { Lo }\end{array}$ & $\begin{array}{c}\text { ALIGN-R } \\
\text { Dor }\end{array}$ & $\begin{array}{c}\text { NoNAS } \\
\text { CODA }\end{array}$ & $\begin{array}{c}\text { No } \\
\text { NAS }\end{array}$ & $\begin{array}{c}\text { SPREAD } \\
\text { LO }\end{array}$ \\
\hline \hline $\mathrm{A}$ & $\mathrm{A}$ & $\mathrm{A}$ & $\mathrm{A}$ & $\mathrm{A}$ & $\mathrm{A}$ \\
\hline
\end{tabular}

The violation of Contiguity encodes the discontinuity of the affix in the output; the segmental content [ka.an] is given by the remaining constraint violations.

A tableau makes clear why the optimal form is circumfixal.

(39) kabukiran 'fields'

\begin{tabular}{|c|c|c|c|}
\hline & $\begin{array}{l}\text { CONTIG } \\
\text { (AFFIX) }\end{array}$ & $\begin{array}{l}\text { CONTIG } \\
\text { (Stem) }\end{array}$ & ONSET \\
\hline ka-bukid-an & A & & \\
\hline ka-bukid-a.an & A & & $* !$ \\
\hline ka.a-bukid-n & A & & $* !$ \\
\hline ka-buk-an-id & A & $* !$ & \\
\hline ka-an-bukid & $<\mathrm{A}>$ ! & & \\
\hline bukid-ka.an & $<\mathrm{A}>$ ! & & \\
\hline
\end{tabular}

The first candidate retains the distinctive discontinuity of the affix as well as the unmarked continuity of the stem by circumfixing the affix around the root. The second and third candidates do so too, but they violate ONSET, a constraint which requires syllables to begin with a consonant (Prince \& Smolensky 1993). The fourth retains the ConTIGUITY (AFFIX) violation but fatally violates ConTIGUITY (STEM). Candidates five and six fatally respect Contiguity (AfFIX), a faithfulness violation $(\langle\mathrm{R}\rangle)$ since violation of this constraint is distinctive for the affix in question.

The analysis of circumfixes and infixes offered here makes direct reference to a surface property common to both: discontinuous morphemes. Circumfixes 
are treated as distinctive violations of CONTIGUITY (AFFIX), infixes as distinctive violations of CONTIGUITY (RoOT). ${ }^{9}$

4.4. ZERO AFFIXES. Morphological categories are not always overtly marked. Morpheme-based analyses often resort to zero-affixes to explain pairs like the following. ${ }^{10}$

(40) Zero-affixation

$\begin{array}{cl}\text { SINGULAR } & \text { PLURAL } \\ \text { deer } & \text { deer- } \varnothing \\ \text { fish } & \text { fish- } \varnothing \\ \text { elk } & \text { elk- } \varnothing\end{array}$

The use of a zero affix is not totally ad hoc: its 'presence' may be used to block the addition of the elsewhere plural $-s$. The problem is that any use of a zero affix runs into an obvious dilemma: how do we know that the $\emptyset$ is a suffix rather than a prefix (or infix or circumfix)?

What is marked about zero plurals on the surface is surely the lack of an overt affix. That is, zero-affixation violates EXPONENCE, the requirement that every morpheme have a phonological reflex. Direct OT represents such a morpheme as:

(41) Plural

\begin{tabular}{|c|}
\hline EXPON \\
\hline \hline $\mathrm{A}$ \\
\hline
\end{tabular}

This avoids entirely the issue of where the morpheme is located (prefix, suffix, etc.) by directly recognizing the fact that the morpheme is not overtly repre-

${ }^{9}$ Circumfixes occur with both V-and C-initial stems. Examples with other circumfixes include (Schachter \& Otanes 1972:288, 315):

pag-sulat-an 'write in/on' ma-lamig-an 'feel cold' pag-awit-an 'sing at/in' ma-anghang-an 'feel a biting taste'

The analysis so far doesn't select pag-awit-an over * $p$-awit-agan, as an anonymous reviewer points out. Align-R (STEM, WD), proposed for Tagalog in $\$ 1$, does this as follows:

\begin{tabular}{|c||c:c:c|}
\hline & $\begin{array}{c}\text { ConTIG } \\
\text { (RoOT) }\end{array}$ & $\begin{array}{c}\text { ConTIG } \\
\text { (AfFIX) }\end{array}$ & $\begin{array}{c}\text { Align-R } \\
\text { (STEM,WD) }\end{array}$ \\
\hline \hline pag-awit-an & & $\mathrm{A}$ & $*$ \\
\hline p-aw-ag-it-an & $* !$ & $\mathrm{A}$ & $*$ \\
\hline p-awit-agan & & $\mathrm{A}$ & $* * !$ \\
\hline
\end{tabular}

The second candidate fails because it has an unasked for discontinuous root $(a w . . . i t)$; the third because the root is needlessly misaligned.

${ }^{10}$ Lieber (1992 and references therein) distinguishes zero-affixation from relisting. She analyzes English as a relisting language. The argument I wish to make here, that zero-affixation is simply violation of EXPONENCE, can also be made with her cases of zero-affixation. 
sented. Note, however, that 41 blocks suffixation of default $-s$; suffixation of default $-s$ would result in a faithfulness violation, since the distinctive violation of EXPONENCE would not be realized.

4.5. Subtractive morphology. Subtractive morphology, in which a grammatical category is marked by deletion of stem material, poses a major obstacle to morpheme-based theories of morphology, as Anderson (1992) has pointed out. The reason is that there seems to be no plausible way to characterize deletion as addition of an affix. Anderson takes this as evidence that at least some morphology is processual and thus 'a-morphous' as he puts it. A comprehensive discussion of subtractive morphology is found in Weeda 1992:chap. 4.

A paradigm case of subtractive morphology is found in Tohono O'odham (Zepeda 1983); 42 shows how the perfective form of verbs is formed by deleting the final syllable of the stem.

$\begin{array}{lll}\begin{array}{l}\text { STEM } \\ \text { cikapana }\end{array} & \text { PERFECTIVE } & \\ \text { bisiceka } & \text { bisice } & \text { 'worked' (surface }\left[\text { cik }^{\mathrm{h}} \mathrm{p}^{\mathrm{h}}\right] \text { ) } \\ \text { bisiceeded' (surface }\left[\mathrm{bisc}^{\mathrm{h}}\right] \text { ) }\end{array}$

A number of analyses have been proposed (Hale 1965, Mathiot 1973, Martin 1988, Lombardi \& McCarthy 1991, Hill \& Zepeda 1992, Weeda 1992), most of them highly processual. The Lombardi \& McCarthy analysis, for instance, treats subtraction as parsing out a light syllable at the end of the verb base and then deleting it. In that sense, each of these analyses is $a$-morphous and supports Anderson's claim that subtractive morphology is inherently processual.

OT seems to be no better situated to handle the subtractive part of subtractive morphology. Benua 1995 offers a thorough OT analysis of the irregular phonology involved in subtractive morphology but leaves open the representation of the subtractive morpheme itself. Fitzgerald \& Fountain 1995 suggest a constraint TRUNC which requires that there be material from the input string which is not included in the output. ${ }^{11}$ This captures the facts directly but at a cost: it requires creating an ad hoc constraint (TRUNC) and it encodes the shape of a morpheme as a constraint rather than as an input, the standard repository of morpheme peculiarities in OT. ${ }^{12}$

In direct OT subtractive morphology can be characterized as distinctive violation of the faithfulness constraint Parse. Unlike Trunc, the family of ParSe constraints (Parse Feature, Parse Segment, Parse Syllable) already plays a central role in standard OT (see McCarthy \& Prince 1993a: 91 for PARSESYLL).

${ }^{11}$ Fitzgerald and Fountain argue that it is a segment that is deleted in Tohono O'Odham rather than a syllable, basing their analysis on a different set of underlying forms for the language than is usually assumed. If they are correct in this matter the desideratum involved is PARSE SEgMeNT rather than Parse Syllable.

12 Declarative phonology represents all morphemes as constraints and a similar approach has been advocated for OT in Hammond 1995 and Russell 1995 (see $\$ 5$ for discussion). My objection to Fitzgerald and Fountain's analysis is that they represent some types of morphemes with input strings (stems and nonsubtractive affixes) and others with constraints (subtractive affixes); McCarthy and Prince's (1993c) analysis of reduplication is guilty of the same excess (see $\$ 4.6$ for discussion). 
The desideratum for the Tohono O'odham perfective is simply:

(43) Tohono O'odham perfective ${ }^{13}$

\begin{tabular}{|c|}
\hline $\begin{array}{c}\text { PARSE } \\
\text { SYLL }\end{array}$ \\
\hline \hline $\mathrm{A}$ \\
\hline
\end{tabular}

The fact that it is the last syllable of the word that is underparsed need not be stipulated as it is in the Lombardi \& McCarthy analysis. Rather, it results from the ALIGN-L ( $f, W D$ ) desiderata: underparsing any nonfinal syllable would alter the desired (mis)alignment of distinctive features.

This analysis is in fundamental agreement with Anderson's claim that subtractive morphology cannot be characterized as affixal, but it does not support his claim that (any) morphology is inherently processual. Rather, it supports the claim that morphemes are represented by the constraints they violate, by the evils they do, so to speak. There is nothing mysterious about a subtractive morpheme on this account: it merely involves distinctive violation of a constraint that is generally very highly ranked.

4.6. Reduplication. Reduplicative morphology has been elegantly analyzed as affixation of a prosodic template to a base (Marantz 1982, McCarthy $\&$ Prince 1986, 1988, Steriade 1988). Direct OT represents the introduction of empty prosodic structure directly as a violation of FILL. The syllable-sized reduplicant in Nootka (Stonham 1990) may be represented as 44.

(44) Nootka reduplicant

\begin{tabular}{|c|}
\hline FILL \\
SYLL \\
\hline \hline $\mathrm{A}$ \\
\hline
\end{tabular}

The representation of reduplication is thus entirely parallel with the representation of subtraction, as comparison of 44 and 43 shows: reduplication violates FILL, subtraction violates PARSE.

The shape of the reduplicant in standard OT is currently treated rather indirectly (McCarthy \& Prince 1993a, 1995). The underlying form, RED, is completely abstract and has no shape of its own; its shape is determined by surface constraints like RED $=\sigma, \operatorname{RED}=\sigma_{\mu \mu}$, and so on. As with Fitzgerald \& Fountain's analysis of subtractive morphology it requires an ad hoc abstract morpheme (RED) and a family of ad hoc constraints to regulate it, multiplying

\footnotetext{
${ }^{13}$ According to Lombardi and McCarthy and Hill and Zepeda only light syllables undergo truncation, but evidence for this (Hill \& Zepeda, 384-85) seems to be rather weak. Hill and Zepeda base the claim on eleven words (their $36 \mathrm{a}-\mathrm{k}$ ) which they argue 'all exhibit bimoraic syllables at the right edge' (385). But the last three words (eñga 'owning', dada 'arriving' and cicwi 'playing') would seem to end in short vowels and four of the remaining words are monosyllabic: $k a$ : 'hearing', $k i$ : 'living', mu: 'wounding by shooting', and bia 'dishing out food', and thus should not be subject to the rule anyway. I leave this all open for now and choose the more general solution.
} 
theoretical primes to explain marked phenomena. The irony of course is that the markedness of the phenomena is not captured by the analysis.

RPM expresses the markedness of reduplicative and subtractive morphology directly with desiderata involving faithfulness (PARSE, FILL) violations. The centrality of faithfulness in phonology makes distinctive violation of it a marked option in the morphology. We can explain the fact that subtractive morphology is much less common than reduplicative morphology in the same terms: languages generally rank PARSE above FILL to ensure that information is not lost (cf. Kiparsky 1993).

4.7. Templatic morphology. A major challenge for direct OT is how to model templatic morphology that is not reduplicative, such as that found in Classical Arabic (McCarthy 1979, McCarthy \& Prince 1990), Yawelmani (Archangeli 1991) or Choctaw (Lombardi \& McCarthy 1991, Hammond 1993, Ulrich 1994). There are two issues here. First, it is not always possible to translate the inherently positive notion of prosodic templates into constraint violations. Second, for Semitic languages at least, it is not possible to encode the linear order of putative roots like $k-t-b$ 'write' or $d-r-b$ 'beat', for such roots are inherently not prosodified and thus do not violate the constraints necessary for encoding them. For such roots representation as pure markedness seems to be impossible.

Since the subject is fairly broad, I'll limit discussion to the prosody of three areas of Classical Arabic: the binyanim, the masdars, and the diminutives and broken plurals. Again, the problems are (i) how to do without prosodic templates and (ii) how to encode unsyllabifiable roots. As a neutral way of indicating templatic shape I use the CV-notation developed in McCarthy 1979 (and later abandoned). As will be clear, this is merely expository; the lesson of prosodic morphology, that templates are NOT based on Cs and Vs, is not meant to be forgotten here but embraced.

4.7.1. Binyanim. The fifteen binyanim are based on the six prosodic shapes below. ${ }^{14}$

(45) Basic prosodic shapes of Classical Arabic verb stems

\begin{tabular}{|l|c|}
\hline Binyanim & $\begin{array}{c}\text { Basic } \\
\text { Shape }\end{array}$ \\
\hline \hline 1 & CV.CVC \\
\hline $2,4,5$ & CVC.CVC \\
\hline 3,6 & CVV.CVC \\
\hline $7,8,9$ & CCV.CVC \\
\hline $10,12,13,14,15$ & CCVC.CVC \\
\hline 11 & CCVV.CVC \\
\hline
\end{tabular}

${ }^{14}$ I abstract away here from additional prefixal material: binyan 5 has the CVC.CVC shape of 2 plus a CV prefix; 6 has the CVV.CVC shape of 3 plus a CV prefix. 
I take binyan 1 as basic and 'derive' the others from it, as it were, by means of distinctive constraint violations. There are two reasons for choosing 1 as basic. Semantically it tends to carry the least information (e.g., 'write' as compared to 'cause to write', 'subscribe', etc.); prosodically it has the best shape, alternating single vowels with single consonants, making this the least marked choice for desiderata. Thus the representation for the root 'write' includes alignment violations but no vowel features, corresponding to a linear representation something like [kE.tEb], with $\mathrm{E}$ representing a maximally underspecified vowel.

(46) 'write'

\begin{tabular}{|c|c|c|c|}
\hline $\begin{array}{c}\text { ALIGN } \\
\text { COR }\end{array}$ & $\begin{array}{c}\text { ALIGN } \\
\text { LAB }\end{array}$ & $\begin{array}{c}\text { No } \\
\text { DOR }\end{array}$ & $\begin{array}{c}\text { No } \\
\text { STOP }\end{array}$ \\
\hline \hline R & RR & R & RRR \\
\hline
\end{tabular}

This solves the problem of how to represent a triliteral root: it is treated rather like a verbal root in Tiv, lacking underlying vowel features but still having a prosodic shape. These vowel features are of course supplied by other morphemes (as will be seen shortly).

The remaining prosodic shapes in 45 differ minimally from the first in the structure of the initial syllable. The second and fifth shapes have a coda consonant; the third and sixth a complex nucleus; the fourth, fifth and sixth a complex onset. Given well-studied constraints on syllable structure, No CoMPLEX ONs, No Complex Nuc and No Coda, we can characterize the surface differences in 47 (assuming final consonant extrametricality here).

(47)

\begin{tabular}{|l|c|c|c|c|}
\hline Binyanim & $\begin{array}{c}\text { Basic } \\
\text { Shape }\end{array}$ & $\begin{array}{c}\text { NoCPLX } \\
\text { ONS }\end{array}$ & $\begin{array}{c}\text { NoCPLX } \\
\text { NuC }\end{array}$ & $\begin{array}{c}\text { No } \\
\text { CoDA }\end{array}$ \\
\hline 1 & CV.CVC & & & \\
\hline $2,4,5$ & CVC.CVC & & & $\mathrm{A}$ \\
\hline 3,6 & CVV.CVC & & $\mathrm{A}$ & \\
\hline $7,8,9$ & CCV.CVC & $\mathrm{A}$ & & \\
\hline $10,12-15$ & CCVC.CVC & $\mathrm{A}$ & & $\mathrm{A}$ \\
\hline 11 & CCVV.CVC & $\mathrm{A}$ & $\mathrm{A}$ & \\
\hline
\end{tabular}

We can now represent each of these shapes directly by the constraints they violate. The phonological representation of binyanim 2,4 , and 5 is distinctive violation of No CoDA.

(48) Binyanim 2, 4, 5

\begin{tabular}{|c|}
\hline No \\
CODA \\
\hline \hline $\mathrm{A}$ \\
\hline
\end{tabular}


That is, the shapes of $\mathrm{B} 2, \mathrm{~B} 4$, and $\mathrm{B} 5$ differ from that of the root shape (CV.CVC) by the presence of an additional coda consonant; this is the sole surface property that defines these binyanim. The defining surface property for binyanim 3 and 6 , on the other hand, is violation of No Complex NuCleus, their unique desideratum. Binyanim 7, 8 and 9 distinctively violate No COMPLEX ONSET.

(49) Binyanim 3, 6

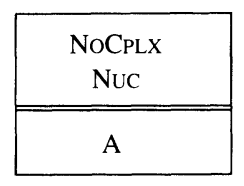

(50) Binyanim 7, 8, 9

\begin{tabular}{|c|}
\hline $\begin{array}{c}\text { NoCPLX } \\
\text { ONS }\end{array}$ \\
\hline $\mathrm{A}$ \\
\hline
\end{tabular}

The remaining binyanim are doubly marked. One set has both a coda consonant and a complex onset; the other has a complex nucleus and a complex onset.

(51) Binyanim 10, 12, 13, 14, 15

\begin{tabular}{|c|c|}
\hline No & NoCPLX \\
CODA & ONS \\
\hline \hline $\mathrm{A}$ & $\mathrm{A}$ \\
\hline
\end{tabular}

(52) Binyan 11

\begin{tabular}{|c|c|}
\hline $\begin{array}{c}\text { NoCPLX } \\
\text { NuC }\end{array}$ & $\begin{array}{c}\text { NoCPLX } \\
\text { ONS }\end{array}$ \\
\hline \hline $\mathrm{A}$ & $\mathrm{A}$ \\
\hline
\end{tabular}

The formal markedness of these doubly-marked binyanim is reflected directly by their commonness: binyanim 10-15 are rare in Classical Arabic and are hardly used in the modern language (Holes 1995:85).

The representations above do not say anything about the constraint violation being realized on the initial syllable of the root. Independent considerations guarantee this. To see how, notice an important surface generalization that holds for all binyanim: they all begin with a bimoraic foot $(\mathrm{LL} \text { or } \mathrm{H})^{15}$-that is, they respect ALIGN-L (STEM, FT). Realizing a complex nucleus or an additional coda consonant on the second syllable of the root (kE.tEEb, ke.tEbb) would violate ALIGN by creating an unfooted single light syllable at the beginning of the stem; hence the first syllable is made heavy. This accounts for everything but the initial complex onset in binyanim 7-15, which is due to a

${ }^{15}$ Kager 1993 analyzes binyanim as left-headed for this reason. See Itô 1990 for the claim that Japanese hypocoristic templates must begin with a bimoraic foot: [LL], [HH], [HLL], [HL], [LLLL], [LLL] and [LLH] are well-formed hypochoristics but $[\mathrm{LH}]$ is not. 
separate consideration: syllable structure is stricter within a morpheme than at the edge (Steriade 1982, 1988). Again, this makes the best place to complicate syllable structure in a CV.CVC root the initial syllable, CCV.CVC being less marked than CV.CCVC.

Note that the symmetry of the system here is only possible if one treats complex onsets, complex nuclei, and simplex codas as parallel. This is not possible in prosodic morphology (McCarthy \& Prince 1986, 1990, 1993a) since onset complexity is irrelevant to the prosodic hierarchy. Within direct OT, however, CCV, CVV and CVC form a natural class of deviations away from $\mathrm{CV}$. Each violates the constraints on onset, nucleus and coda exactly once.

The full set of fifteen triliteral binyanim for Classical Arabic is derived by adding prefixal material, vowel quality, and binyan-specific consonant material. From here on, direct OT mirrors McCarthy's (1979) analysis, aligning consonantal and vocalic features with the beginning of a word and spreading them rightwards when necessary. To illustrate, I'll discuss two representative cases, kuttib and kuutib.

I begin with kuttib. Three morphological elements must be considered: the root $k E t E b$ (46 above), the shape of binyan 2 ( 48 above) and the perfective passive vocalic melody $u$ - $i$.

(53) Perfective Passive

\begin{tabular}{|c|c|}
\hline No & $\begin{array}{c}\text { SPREAD } \\
\text { RD }\end{array}$ \\
\hline \hline $\mathrm{A}$ & $\mathrm{A}$ \\
\hline
\end{tabular}

The optimal candidate is the one that best satisfies these three sets of desiderata. In the following tableau the first candidate realizes every desideratum and incurs no additional constraint violations.

(54) kuttib

\begin{tabular}{|c|c|c|c|c|c|c|c|}
\hline & $\begin{array}{c}\text { No } \\
\text { CODA }\end{array}$ & ONS & $\begin{array}{c}\text { NoCPLX } \\
\text { ONS }\end{array}$ & $\begin{array}{c}\text { NoCplx } \\
\text { NuC }\end{array}$ & $\begin{array}{l}\text { ALN } \\
\text { RD }\end{array}$ & $\begin{array}{l}\text { No } \\
\text { RD }\end{array}$ & $\begin{array}{c}\text { SPREAD } \\
\text { HI }\end{array}$ \\
\hline kut.tib & A & & & & & A & A \\
\hline kot.tib & A & & & & & A & $<A>$ ! \\
\hline kut.teb & A & & & & & A & $<\mathrm{A}>$ ! \\
\hline kit.tib & A & & & & & $<\mathrm{A}>$ ! & A \\
\hline kut.ti.bi & A & & & & & A & $A^{*} !$ \\
\hline kit.tub & A & & & & $* !$ & A & A \\
\hline kuu.tib & $<A>$ ! & & & * & & A & A \\
\hline ktu.tib & $<A>!$ & & $*$ & & & A & A \\
\hline uk.tib & A & $* !$ & & & & A & A \\
\hline ku.tib & $\langle A\rangle$ ! & & & & & A & A \\
\hline
\end{tabular}


Candidates two through four fail because they lack desiderata $(\langle\mathrm{A}\rangle)$ of the perfect passive; candidate five fails because it has a constraint violation that is not a desideratum (an additional violation of SPREAD HI for the extra vowel); six and nine fail because they have violations that are not desiderata; and candidates seven, eight, and ten lack the single desideratum of the second binyan.

A change in binyan means a change in desiderata. Consider the same field of candidates in the third binyan of the perfective passive.

(55) kuutib

\begin{tabular}{|c|c|c|c|c|c|c|c|}
\hline & $\begin{array}{c}\text { No } \\
\text { CODA }\end{array}$ & ONS & $\begin{array}{c}\text { NoCplX } \\
\text { Ons }\end{array}$ & $\begin{array}{c}\text { NoCPLX } \\
\text { NuC }\end{array}$ & $\begin{array}{c}\text { ALN } \\
\text { RD }\end{array}$ & $\begin{array}{l}\text { No } \\
\text { RD }\end{array}$ & $\begin{array}{c}\text { SPREAD } \\
\text { HI }\end{array}$ \\
\hline kut.tib & $* !$ & & & $<A>$ & & A & A \\
\hline kot.tib & $* !$ & & & $<A>$ & & A & $<A>$ \\
\hline kut.teb & $* !$ & & & $<A>$ & & A & $<\mathrm{A}>$ \\
\hline kit.tib & $* !$ & & & $<A>$ & & $<A>$ & A \\
\hline ku.ti.bi & & & & $<\mathrm{A}>$ ! & & A & $\mathrm{A}^{*}$ \\
\hline kit.tub & $* !$ & & & $<\mathrm{A}>$ & * & A & A \\
\hline kuu.tib & & & & A & & A & A \\
\hline ktu.tib & & & $* !$ & $<A>$ & & A & A \\
\hline uk.tib & $* !$ & $*$ & & $<\mathrm{A}>$ & & A & A \\
\hline ku.tib & & & & $<\mathrm{A}>$ ! & & A & A \\
\hline
\end{tabular}

Violation of No CODA and No Complex ONSET are desideratum for B3, ruling out candidates one through four, six, eight and nine. Violation of No Complex Nuc, on the other hand, is a desideratum for B3, ruling out candidates five and ten and leaving candidate seven as the winner.

The infixal material in binyan 8 requires comment. Here the shape is $\mathrm{CtV}$. CVC, with the second consonant prelinked (in the terminology of another day) to the melody: e.g. [k-t-a.sab] 'to earn'. Focusing on the result of all this, a shocking violation of CONTIGUITY, we immediately see the analysis: binyan 8 has an infix. The representation in 56 both describes this and guarantees it.

(56) Binyan 8

\begin{tabular}{|c|c:c|}
\hline $\begin{array}{c}\text { CONTIG } \\
\text { (STEM) }\end{array}$ & No & No \\
\hline \hline $\mathrm{A}$ & $\mathrm{A}$ & $\mathrm{A} T \mathrm{P}$ \\
\hline
\end{tabular}

The best place to add a stop is after the first consonant and before the first vowel-any later results in a fatal violation of ALIGN-STOP since the first vowel creates a peak between the inserted stop and the beginning of the word. 
This nontemplatic approach to templatic morphology has a number of advantages. As Mike Hammond (p.c.) points out, it solves the problem with medial gemination in forms like kattab (*kat.bab), problematic in McCarthy 1979 and McCarthy \& Prince 1986. The form kattab has the same feature-alignment violations as katab, with [t] one peak [b] two peaks from the beginning; *katbab has the features for [b] better aligned (only one peak from the edge) than the desiderata allow. Second, this analysis greatly simplifies the representation of the various oblique binyanim: the prosodic shapes of binyanim 2-9 are each identified by a single distinctive feature, those of $10-15$ by two. ${ }^{16}$ Third, the rarity of binyanim 10-15 receives formal explanation: the forms are rare because they are more marked. Finally, the nontemplatic approach makes Arabic stems look like those of other languages, reducing the number of basic morphological types from two (regular and interdigitating) to one.

4.7.2. MASDARS. As McCarthy (1979:180) points out, masdars (a type of verbal noun) generally have the same shapes as their perfective verb counterparts but with the final syllable CVVC rather than CVC. ${ }^{17}$

(57) Masdars

\begin{tabular}{|l|l|}
\hline \multicolumn{1}{|c|}{ Binyanim } & Masdars \\
\hline \hline 1 & CV.CVVC \\
\hline $2,4,5$ & CVC.CVVC \\
\hline 3,6 & CVV.CVVC \\
\hline $7,8,9$ & CCV.CVVC \\
\hline $10,12,13,14,15$ & CCVC.CVVC \\
\hline 11 & CCVV.CVVC \\
\hline
\end{tabular}

From the surface forms in 57 it is immediately clear how the nominal masdars differ from the corresponding verbs: the masdars alone have a foot (the final CVVC) that is misaligned with the beginning of the stem. Taking this to be the defining characteristic of a nominal we may represent them as their verbal counterparts in $48-52$ plus the distinctive feature in (58).

\footnotetext{
${ }^{16}$ Compare McCarthy and Prince's (1986:65) belabored characterizations of templates such as the following:

CVVCVC $\sigma_{\mu \mu}+\sigma$

$\operatorname{CCVVCVC}(\sigma)+\sigma_{\mu \mu}+\sigma$
}

In later work (McCarthy \& Prince 1990) they are able to give a simple analysis of one (!) of the fifteen basic shapes in Arabic but must still treat all of the binyanim and masdars as complex templates like those above. As Kager (1993) rightly points out, there is no morphological justification in Arabic for treating some templates as complex and others as simple.

${ }^{17}$ Binyan 1 masdars are extremely idiosyncratic; CVCVVC is a common pattern but CVCC and CVCVC occur as well. See McCarthy 1979:183ff for discussion. CVCVC is unmarked according to the present analysis, CVCC is treated below. 
(58) Noun

\begin{tabular}{|c|}
\hline $\begin{array}{c}\text { AliGn-L } \\
\text { (Ft,SteM) }\end{array}$ \\
\hline \hline $\mathrm{A}$ \\
\hline
\end{tabular}

Additional evidence for the distinctiveness of Align-L (FT, STEM) comes from our final set of Arabic data, the diminutives and broken plurals.

4.7.3. Diminutives And broken Plurals. As McCarthy and Prince (1990) make clear, the defining surface characteristic of diminutives and broken plurals is their shape LHX, where $\mathrm{X}$ is $\mathrm{L}, \mathrm{H}$ or nothing depending on the shape of the second syllable of the singular from which they are formed. Representative plurals and the singulars on which they are based are given in 59 .

\begin{tabular}{lllll}
\multicolumn{2}{c}{ SINGULAR } & \multicolumn{2}{c}{ PLURAL } & \\
mak.tab & HL & ma.kaa.tib & LHL & 'office' \\
jun.dab & HL & ja.naa.dib & LHL & 'locust' \\
sul.țaan & HH & sa.laa.țiin & LHH & 'sultan' \\
mif.taah & HH & ma.faa.tiih & LHH & 'key' \\
nafs & H & nu.fuus & LH & 'soul' \\
burd & H & bu.ruud & LH & 'robe'
\end{tabular}

Whereas all of the singulars in 59 begin with a foot $(\mathrm{H})$, none of the plurals do, in violation of ALIGN-L (FT, STEM). What the broken plural brings to the singular is thus an additional misaligned foot. They have the same formal analysis as nominal masdars, supporting the status of ALIGN-L (FT, STEM) violations as the default desideratum for nouns. ${ }^{18}$

We see then that the verbal and nominal systems of Classical Arabic make use of different types of distinctive constraint violations. The verbal paradigm uses violation of basic syllable structure constraints while the nominal paradigm (masdars, diminutives, broken plurals) is marked by misalignment. The only remaining templates used in Arabic are nominal CCVC, CCVVC and CVCC, each of which has a syllable less than the basic CV.CVC. These shapes are straightforwardly analyzed as violations of PARSE Syllable, in conjunction with the syllabic constraints already discussed: No CoMPLEX ONS (CCVC, CCVVC), No Complex Nuc (CCVVC) and No Coda (CVCC), as shown in 60 .

${ }^{18}$ Broken Plurals could also be defined by *ALIGN-L (STEM, FT), which requires every stem to begin with a foot. This would explain why LHX singulars often have the same number of misaligned feet as their plurals.

(i) SINGULAR

$\begin{array}{lllll}\text { simaal } & \text { LH } & \text { samaa?il } & \text { LHL 'left hand' } \\ \text { wasiid } & \text { LH } & \text { wasa?id } & \text { LHL 'court' }\end{array}$

The singular forms here already violate ALIGN-L (STEM, FT) and it is not a constraint that can be violated more than once because there is only one left edge per stem. I will not pursue this analysis further here due to space. 
(60) Distinctive features of Classical Arabic morphological shapes

\begin{tabular}{|c|c|c|c|c|c|}
\hline BASIC SHAPE & $\begin{array}{c}\text { NoCplX } \\
\text { ONS }\end{array}$ & $\begin{array}{c}\text { NoCPLX } \\
\text { NuC }\end{array}$ & NoCoDA & $\begin{array}{c}\text { ALIGN-L } \\
\text { (FT, STEM) }\end{array}$ & $\begin{array}{c}\text { Parse } \\
\text { Syllable }\end{array}$ \\
\hline CV.CVC & & & & & \\
\hline CV.CVVC & & & & A & \\
\hline CVC.CVC & & & A & & \\
\hline CVV.CVC & & A & & & \\
\hline CCV.CVC & A & & & & \\
\hline CVC.CVVC & & & A & A & \\
\hline CVV.CVVC & & A & & A & \\
\hline CCV.CVVC & A & & & A & \\
\hline CCVC.CVC & A & & A & & \\
\hline CCVV.CVC & A & A & & & \\
\hline CCVC.CVVC & A & & A & A & \\
\hline CCVV.CVVC & A & A & & A & \\
\hline CVCC & & & A & & A \\
\hline $\mathrm{CCVC}$ & A & & & & A \\
\hline CCVVC & A & A & & & A \\
\hline
\end{tabular}

Rather than proving problematic for RPM, Arabic morphology yields to it easily; the starting point is getting past the misguided notion of triliteral roots. Once roots are described in terms of a prosodic shape (as they are in all other languages) the generalizations upon which the morphology is based can be given in terms of pure markedness: worse syllable structure for verbs, misalignment and underparsing for nouns.

This concludes the discussion of marked morphology. I've tried to show that even quite exotic types of morphology can be represented in terms of pure markedness. I've simultaneously shown that violations of many types of constraint can be morphologically distinctive, including constraints governing syllable structure, faithfulness, contiguity, and alignment. Whether every constraint can be distinctive in this way is an open question and will remain one at least until we know what the universal set of constraints is.

5. COMPARISON WITH OTHER PROPOSALS. Up to this point I have been at pains to compare morphemes as constraint violations (RPM) with a more traditional view of morphemes as linear strings, but there is a third view which treats morphemes as constraints. This has been developed in a number of frameworks 
including declarative phonology (Bird 1990, 1995, Coleman 1991, Scobbie 1991, 1992), Wortdesign (Neef 1996), and OT (Hammond 1995, Russell 1995).

Neef's penetrating analysis of German verbal inflection may serve as an illustration. Based on regular verb forms like geh-st 'you go' and geh-t 'you (pl.) go' Neef proposes constraints like the following:

(59) 2nd person singulars end in -st

(60) 2 nd person plurals end in $-t$

Neef's approach requires a potentially infinite number of language-specific constraints since all inflectional affixes are represented with constraints like 59 and 60. This is even clearer in the case of declarative phonology and the OT approaches cited above, according to which every morpheme is a constraint: Hammond (1995) for instance proposes an English constraint that requires CAT to be phonologically realized as [kæt].

Space precludes an adequate analysis of these proposals. I will comment on two shortcomings I think they share. The first is that these proposals merely shift the burden of representation from one area to another: where other theories have underlying representations and no constraints these theories have constraints and no underlying representations. This is most clearly seen in declarative phonology and in Hammond 1995 and Russell 1995: every underlying form is replaced by a corresponding constraint.

The second property these proposals share is that they require an infinite number of constraints, raising potentially serious questions about restrictiveness and learnability. This need not be fatal, of course, if some other way of constraining the theory is in place. But it does introduce an odd discrepancy into constraints. There are now two kinds of constraints: morpheme-specific ones $(\mathrm{CAT}=[\mathrm{kæt}]$, etc.) that regulate the arbitrary relation between sound and meaning and entirely general ones (sonority sequencing, etc.) that define well-formedness conditions independent of meaning. Calling both things constraints does not make them the same type of thing.

Whatever the faults of direct OT, I believe it avoids these two. Rather than creating new constraints for old underlying representations, direct OT makes constraint-violations do double duty: they serve both as representations AND as evaluations. It thus LESSENS the burden of representation rather than merely shifting it. As for the second point, no new constraints or types of constraints are added-as we have seen, even quite exotic types of morphology can be represented with violations of very basic constraints already found in OT. Constraints remain universal; morphemes differ merely as to which constraints they violate and by how much.

6. Conclusion. Constraint violations tell us what is marked about a morpheme. Given a sufficiently detailed set of constraints it is possible to distinguish phonologically distinct morphemes directly in terms of the constraints they violate. The representation of a morpheme is then given purely in terms of markedness.

In terms of morphology, direct OT provides a principled and completely unified theory of representation. The set of distinctive features used to represent 
morphemes-from roots and affixes to subtraction, reduplication, and templates-is simply the set of well-formedness constraints that is independently needed to evaluate them. Marked morphology is then just that subset of morphology that requires distinctive violation of high-ranked constraints like PARSE, FILl and No Coda; such morphology is rare across languages precisely because the constraints it distinctively violates are so basic to the structure of language.

In terms of phonology, direct OT provides an explicit and restrictive theory of representation throughout the grammar, avoiding the general problem of impossibility by making desiderata and surface forms the same types of objects. It also abandons the stipulative use of linear order in phonology and guarantees the permanent underspecification of unmarked structure. Finally, it reduces the theory of representation to a theory of markedness: just as standard OT uses markedness to evaluate forms, direct OT uses it to represent them.

\section{REFERENCES}

Anderson, Stephen R. 1992. A-morphous morphology. Cambridge: Cambridge University Press.

ArChangeli, Diana. 1984. Underspecification in Yawelmani phonology and morphology. Cambridge, MA: MIT dissertation. [Published, New York: Garland, 1988.]

- 1991. Syllabification and prosodic templates in Yawelmani. Natural Language and Linguistic Theory 9.231-83.

— Press.

ARONOFF, MARK. 1976. Word formation in generative grammar. Cambridge, MA: MIT Press.

Bauer, Laurie. 1988. A descriptive gap in morphology. Yearbook of Morphology $1.17-28$.

Beckman, Jill N.; Laura Walsh; and Suzanne Urbanczyk (eds.) 1995. Papers in optimality theory. (University of Massachusetts Occasional Papers in Linguistics, 18.) Amherst, MA: Graduate Linguistic Student Association.

Benua, LaURA. 1995. Identity effects in morphological truncation. In Beckman et al. $1995,77-136$.

BIRd, STEVEN. 1990. Constraint-based phonology. Edinburgh: University of Edinburgh dissertation.

- 1995. Computational phonology: A constraint-based approach. Cambridge University Press.

Blevins, Juliette. 1995. The syllable in phonological theory. In Goldsmith 1995 , 206-244.

Cairns, Charles E. 1988. Phonotactics, markedness and lexical representation. Phonology 5.209-236.

Chomsky, Noam. 1993. A minimalist program for linguistic theory. The view from building 20: Essays in linguistics in honor of Sylvain Bromberger, ed. by Kenneth Hale and Samuel Jay Keyser, 1-52. Cambridge, MA: MIT Press.

Coleman, John. 1991. Phonological representations. York: University of York dissertation.

Corbin, Danielle. 1987. Morphologie dérivationelle et structuration du lexique. (Linguistische Arbeiten, 193-4.) Tübingen: Max Niemeyer.

DobRIN, LISE M. 1993. On the prosodic integrity of underlying forms: In support of a word-based lexicon. Paper presented at LASSO 22.

Fitzgerald, Colleen, and Amy Fountain. 1995. The optimal account of Tohono 
O'odham truncation. Paper presented at 1995 annual meeting of the Linguistic Society of America, New Orleans.

Fudge, ERIK C. 1969. Syllables. Journal of Linguistics 5.253-86.

Fujimura, Osamu. 1992. Phonology and phonetics: A syllable-based model of articulatory organization. Journal of the Acoustical Society of Japan (English series) 13. 39-48.

- , and Julie B. Lovins. 1978. Syllables as concatenative units. Syllables and segments, ed. by Allan Bell and Joan Hooper, 107-120. Amsterdam: North Holland.

Gnanadesikan, Amalia. 1995. Markedness and faithfulness constraints in child phonology. Amherst, MA: University of Massachusetts, MS.

GoldSMITH, John. 1979. Autosegmental phonology. New York: Garland.

- 1990. Autosegmental and metrical phonology. Oxford: Basil Blackwell.

. 1991. Phonology as an intelligent system. Bridges between psychology and linguistics: A Swarthmore Festschrift for Lila Gleitman ed. by Donna Jo Napoli and Judy Kegl, 247-67 Hillsdale, NY: Lawrence Erlbaum.

- (ed.) 1993. The last phonological rule. Chicago: University of Chicago Press.

- (ed.) 1995. The handbook of phonological theory. Oxford: Basil Blackwell.

Golston, CHRIS. 1996. Prosodic constraints on roots, stems and words. Interfaces in phonology, ed. by Manfred Bierwisch and Ursula Kleinhenz, 172-93. Berlin: Akademie Verlag.

- and HARRY VAN DER HULST. 1996. Stricture is structure. The derivational residue in phonology, ed. by Ben Hermans and Marc van Oostendorp. Amsterdam: John Benjamins.

GreEnBERG, Joseph. 1960. The patterning of root morphemes in Semitic. Word 6.162-81.

HaCken, Pius TEN. 1994. Defining morphology: A principled approach to determining the boundaries of compounding, derivation and inflection. Hildesheim: Georg Olms.

Hale, Kenneth. 1965. Some preliminary observations on Papago morphophonemics. International Journal of *American Linguistics 31.295-305.

Hammond, Michael. 1993. Heavy trochees in Choctaw morphology. Phonology $10.325-36$.

- 1995. There is no lexicon! Tucson: University of Arizona, MS.

Hill, Jane H., and Ofelia ZePeda. 1992. Derived words in Tohono O'odham. International Journal of American Linguistics 58.355-404.

Holes, Clive. 1995. Modern Arabic: Structure, function and varieties. London: Longman.

INKELAS, Sharon. 1994. The consequences of optimization for underspecification. North Eastern Linguistic Society 24.287-302.

-; Orhan Orgun; and Cheryl Zoll. 1994. Subregularities as cogrammars: The theoretical status of nonproductive patterns in grammar. Berkeley, CA: University of California, Berkeley, MS.

Itô, Junko. 1990. Prosodic minimality in Japanese. Chicago Linguistic Society 26(2). 213-39.

Kager, RenÉ. 1993. On defining complex templates. West Coast Conference on Formal Linguistics 12.19-34.

KÁlmán, B. 1965. Das reduzierte Vokal-Phonem in Wogulischen. Proceedings of the 5th International Congress of Phonetic Sciences, ed. by Eberhard Zwirner and Wolfgang Bethge, 278-380. Basel: S. Karger.

KipARSKy, PAul. 1982. Lexical phonology and morphology. Linguistics in the morning calm, ed. by I. S. Yang, 3-91. Seoul: Hanshin.

- 1993. Blocking in non-derived environments. Phonetics and phonology 4: Studies in lexical phonology, ed. by Sharon Hargus and Ellen Kaisse, 277-314. San Diego: Academic Press.

LAKOFF, GEORGE. 1993. Cognitive phonology. In Goldsmith 1993, 117-145.

Lamontagne, Greg, and Keren Rice. 1995. A correspondence account of coalescence. In Beckman et al. 1995, 211-23. 
LeBen, William. 1973. Suprasegmental phonology. Cambridge, MA: MIT dissertation. [Published, New York: Garland, 1979.]

Lieber, Rochelle. 1981. On the organization of the lexicon. Cambridge, MA: MIT dissertation. Bloomington: Indiana University Linguistics Club.

- 1992. Deconstructing morphology: Word formation in syntactic theory. Chicago: University of Chicago Press.

Lombardi, Linda, and John McCarthy. 1991. Prosodic circumscription in Choctaw morphology. Phonology 8.37-72.

MarantZ, AleC. 1982. Re: reduplication. Linguistic Inquiry 13.435-82.

MARTIN, JACK. 1988. Subtractive morphology as disassociation. West Coast Conference on Formal Linguistics 7.229-40.

Mathiot, Madeleine. 1973. A dictionary of Papago usage. Bloomington: Indiana University.

MCCARThy, John J. 1979. Formal problems in Semitic phonology and morphology. Cambridge, MA: MIT dissertation. (Reproduced 1982 by Indiana University Linguistics Club.)

- 1982. Prosodic structure and Expletive Infixation. Language 58.574-90.

- 1995. Extensions of faithfulness: Rotuman revisited. Amherst, MA: University of Massachusetts, MS.

- and Alan S. Prince. 1986. Prosodic morphology. Amherst, MA and Waltham, MA: University of Massachusetts, and Brandeis University, MS.

,- 1988 . Quantitative transfer in reduplicative and templatic morphology. Linguistics in the morning calm 2, ed. by Linguistic Society of Korea. 13-35. Seoul: Hanshin.

- -1990 . Foot and word in prosodic morphology: The Arabic broken plurals. Natural Language and Linguistic Theory 8.209-82.

,- 1993 a. Prosodic morphology I: Constraint interaction and satisfaction. Amherst, MA and New Brunswick, NJ: University of Massachusetts and Rutgers University, MS.

-1 - $1993 \mathrm{~b}$. The emergence of the unmarked: Optimality in Prosodic morphology. North Eastern Linguistic Society 23.333-79.

,$--1993 \mathrm{c}$. Generalized alignment. Yearbook of Morphology 1993.79-153.

,- 1 1994. Prosodic morphology: An overview. Talk presented at the OTS/HIL Workshop of Prosodic Morphology, University of Utrecht.

-1 . 1995. Faithfulness and reduplicative identity. In Beckman et al. 1995, 249-384.

Mohanan, K. P. 1993. Fields of attraction in phonology. In Goldsmith 1993, 61-116.

MoravCsiK, EDITH. 1977. On rules of infixing. Bloomington: Indiana University Linguistics Club.

NeEF, MARTin. 1996. Wortdesign. Eine deklarative Analyse der deutschen Verbflexion. Studien zur deutschen Grammatik. Tübingen: Stauffenburg.

Newman, S. 1944. Yokuts language of California. (Viking Fund Publications in Anthropology, no. 2.) New York: Viking Fund.

Paradis, Carole. 1988. On constraints and repair strategies. Linguistic Review 6. 71-97.

Pater, JoE. 1995. Austronesian nasal substitution and other NC effects. Proceedings of the OTS/HIL Workshop on Prosodic Morphology, ed. by René Kager, Harry van der Hulst and Wim Zonneveld.

Poppe, Nicholas. 1962. Bashkir manual. (Indiana University Publications, Uralic and Altaic Series, vol 36.) Bloomington: Indiana University.

Prince, Alan, and Paul Smolensky. 1993. Optimality theory: Constraint interaction in generative grammar. New Brunswick, NJ and Boulder, CO: Rutgers University and University of Colorado, MS.

Pulleyblank, Douglas. 1986. Tone in lexical phonology. Dordrecht: Reidel.

- 1988. Underspecification, the feature hierarchy and Tiv vowels. Phonology 5.299-326. 
Russell, Kevin. 1995. Morphemes and candidates in Optimality Theory. Winnipeg: University of Manitoba, MS.

Scalise, Sergio. 1984. Generative morphology. Dordrecht: Foris.

Schachter, Paul, and Fe T. Otanes. 1972. Tagalog reference grammar. Berkeley: University of California Press.

Schultink, Henk. 1987. Discontinuity and multiple branching in morphology. Aspects of language, vol 2, ed. by N. Arhammar, 481-91. Amsterdam: Rodopi.

Scobbie, James. 1991. Attribute value phonology. Edinburgh: University of Edinburgh dissertation.

—. 1992. Towards Declarative Phonology. Edinburgh working papers in cognitive science 7.1-26.

Selkirk, Elizabeth O. 1982. The syllable. The structure of phonological representations, part 2, ed. by Harry van der Hulst and Norval Smith, 337-83. Dordrecht: Foris.

Siegel, Dorothy C. 1974. Topics in English morphology. Cambridge, MA: MIT dissertation.

SterIADE, DonCA. 1979. Vowel harmony in Khalkha Mongolian. MIT Papers in Linguistics $1.25-50$.

- 1982. Greek prosodies and the nature of syllabification. Cambridge, MA: MIT dissertation.

- 1987. Redundant values. Chicago Linguistic Society 23(2).339-62.

- 1988. Reduplication and syllable transfer in Sanskrit and elsewhere. Phonology 5.73-155.

- 1995. Underspecification and markedness. In Goldsmith 1995, 114-74.

Stonham, John. 1990. Current issues in morphological theory. Stanford, CA: Stanford University dissertation.

Troubetzkoy, N. S. [1939] 1949. Principes de phonologie, trans. by J. Cantineau. Paris: Klincksieck.

Ulrich, Charles H. 1994. A unified account of Choctaw intensives. Phonology $11.325-39$.

VAGO, RoBert M. 1980. Sound pattern of Hungarian. Washington, DC: Georgetown University Press.

Vennemann, Theo. 1972. On the theory of syllabic phonology. Linguistische Berichte 18.1-18.

- 1973. Phonological concreteness in natural generative grammar. Towards tomorrow's linguistics, ed. by Roger Shuy and C. J. Bailey, 202-19. Washington, DC: Georgetown University Press.

WeEda, Donald Stanton. 1992. Word truncation in prosodic morphology. University of Texas, Austin dissertation.

Wiese, RichaRD. 1995. The phonology of German. Oxford: Oxford University Press. Zepeda, Ofelia. 1983. A Papago grammar. Tucson: University of Arizona Press.

Department of Linguistics

California State University Fresno

Fresno, CA 93740

[chrisg@csufresno.edu]
[Received 22 September 1995; revision received 28 February 1996; accepted 2 April 1996] 